\title{
The p53/microRNA connection in gastrointestinal cancer
}

This article was published in the following Dove Press journal:

Clinical and Experimental Gastroenterology

30 September 2014

Number of times this article has been viewed

\author{
Matjaz Rokavec \\ Huihui Li \\ Longchang Jiang \\ Heiko Hermeking \\ Experimental and Molecular \\ Pathology, Institute of Pathology, \\ Ludwig-Maximilians-Universität \\ München, Munich, Germany
}

Correspondence: Heiko Hermeking

Experimental and Molecular Pathology, Institute of Pathology,

Ludwig-Maximilians-University Munich,

Thalkirchner Strasse 36,

D-80337 Munich, Germany

Tel +4989218073685

Fax +4989218073697

Email heiko.hermeking@med.uni-

muenchen.de

\begin{abstract}
The protein encoded by the TP53 gene is one of the most important suppressors of tumor formation, which is also frequently inactivated in gastrointestinal cancer. MicroRNAs (miRNAs) are small noncoding RNAs that inhibit translation and/or promote degradation of their target messenger RNAs. In recent years, several miRNAs have been identified as mediators and regulators of p53's tumor suppressing functions. p53 induces expression and/ or maturation of several miRNAs, which leads to the repression of critical effector proteins. Furthermore, certain miRNAs regulate the expression and activity of p53 through direct repression of $\mathrm{p} 53$ or its regulators. Experimental findings indicate that miRNAs are important components of the $\mathrm{p} 53$ network. In addition, the frequent genetic and epigenetic alterations of p53-regulated miRNAs in tumors indicate that they play an important role in cancer initiation and/or progression. Therefore, p53-regulated miRNAs may represent attractive diagnostic and/ or prognostic biomarkers. Moreover, restoration of p53-induced miRNAs results in suppression of tumor growth and metastasis in mouse models of cancer. Thus, miRNA-based therapeutics may represent a feasible strategy for future cancer treatment. Here we summarize the current published state-of-the-art on the role of the p53-miRNA connection in gastrointestinal cancer.
\end{abstract}

Keywords: p53, microRNA, cancer, gastrointestinal tract

\section{Introduction}

Gastrointestinal (GI) cancers represent malignant tumors of the GI tract and accessory organs of digestion. They include carcinomas arising in the oral cavity, esophagus, stomach, liver, gallbladder, pancreas, small intestine, large intestine, rectum, and anus. GI cancer represents about $30 \%$ of all tumor incidences and is responsible for approximately $40 \%$ of tumor-related mortality worldwide (Figure 1A and B). ${ }^{1}$ Tumors of the GI tract harbor mutations in the $p 53$ tumor suppressor gene (TP53) with a prevalence ranging from $31 \%$ to $45 \%$ (Figure $1 \mathrm{C}$ ). ${ }^{2}$ The $\mathrm{p} 53$ protein functions as a transcription factor that mediates the response to many cellular stresses, most prominently the DNA damage response. p53 suppresses a variety of malignant processes, thereby representing one of the most important cancer suppressing proteins. ${ }^{3}$ p53 protects against cancer by inducing cellular processes such as apoptosis or cell cycle arrest, thereby preventing the propagation of damaged cells that potentially could give rise to tumors. ${ }^{4,5}$ Moreover, p53 inhibits epithelial to mesenchymal transition (EMT), stemness, and metabolic adaptations, which are typically found in tumors. ${ }^{6}$ In addition, p53 promotes DNA repair, antioxidant defense, and differentiation. On the molecular level, $\mathrm{p} 53$ exerts its tumor suppressive functions by regulating the expression of numerous target genes, mainly by direct binding to specific DNA motifs located in target 


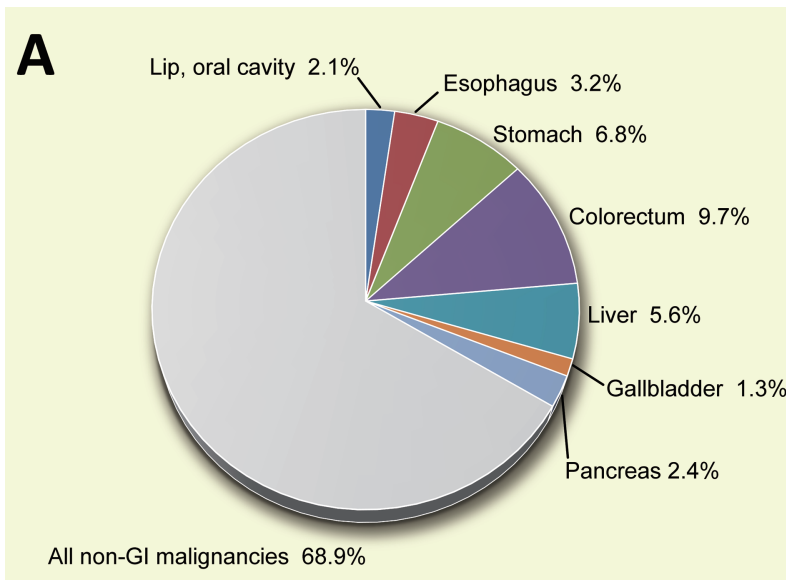

Incidence

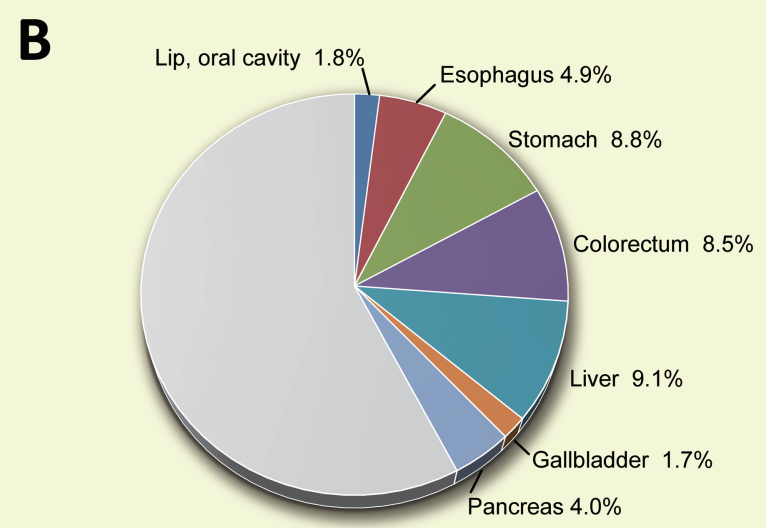

All non-GI malignancies $61.2 \%$

\section{Mortality}

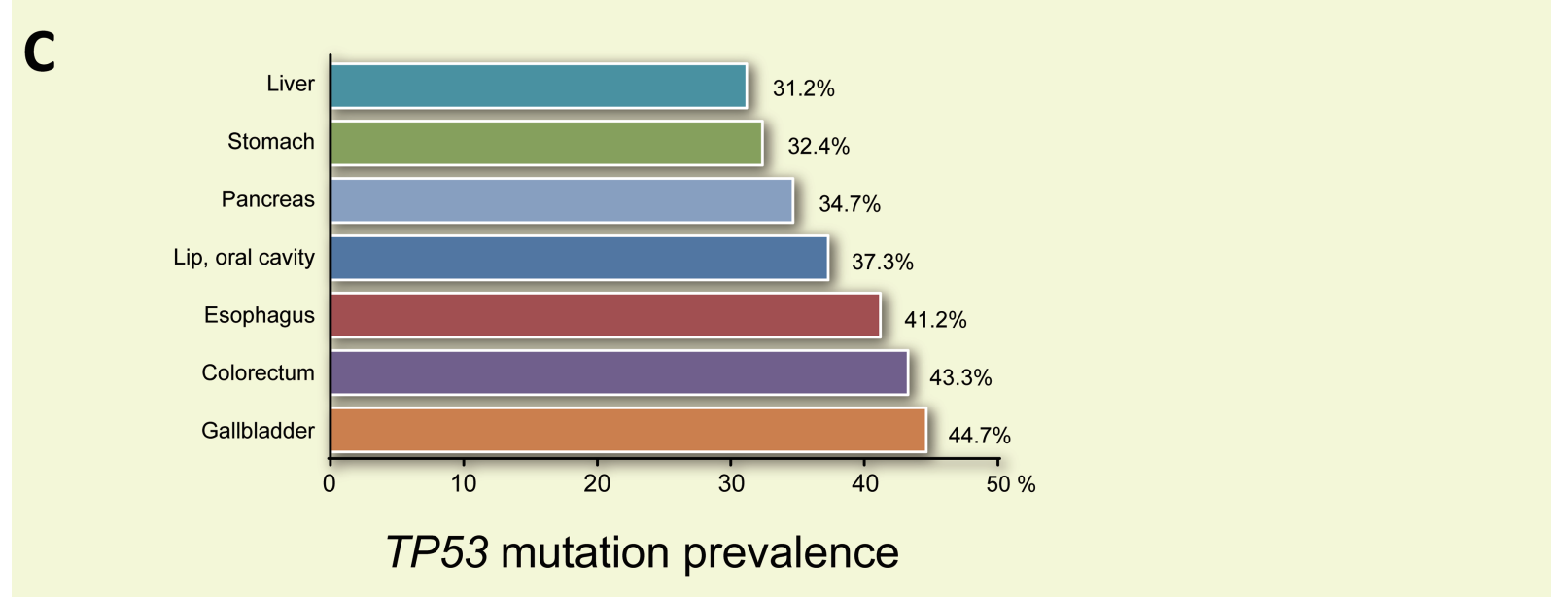

Figure I Incidence (A) and mortality (B) of indicated gastrointestinal (GI) cancers worldwide. (C) Prevalence of mutations in the TP53 gene in the indicated GI cancers.

gene promoters. ${ }^{7}$ Besides $\mathrm{p} 53$-regulated protein expression, p53-induced microRNAs (miRNAs) have emerged as important effectors of $\mathrm{p} 53 .{ }^{8,9}$ The generation of mature miRNAs is a multistage process (see Figure 2) starting with the transcription of miRNA encoding genes to yield the primary miRNA (pri-miRNA). ${ }^{10}$ Next, the pri-miRNA is cleaved by the RNAse III enzyme Drosha, resulting in a $\sim 70$ nucleotide stem-loop-structured miRNA precursor molecule (premiRNA). ${ }^{11}$ The pre-miRNA is transported to the cytoplasm by Exportin 5, where it is cleaved further by the RNAse Dicer. The resulting 20 to 25 bp mature miRNA is incorporated into the miRNA-induced silencing complex (miRISC), which mediates miRNA-induced silencing of target messenger RNAs (mRNAs). ${ }^{12}$ miRNAs bind to $3^{\prime}$-untranslated regions ( $3^{\prime}$-UTR) of mRNAs via their seed sequences, which are conserved seven nucleotide regions in their $5^{\prime}$ region. The association of the miRISC with seed-matching sequences in target mRNAs results in the inhibition of translation and degradation of the target mRNAs. ${ }^{10}$ It has been estimated that $>60 \%$ of human protein coding genes are subject to regulation by miRNAs. ${ }^{13}$ Not surprisingly, miRNA-mediated regulation has been implicated in almost all physiological and pathophysiological processes. ${ }^{10}$ Interestingly, several miRNAs may also be of use for diagnostic, prognostic, and therapeutic applications in GI-cancers. ${ }^{14-18}$ Extracellular miRNAs have been detected in blood serum. These miRNAs are either secreted by living cells via exosomes or microvesicles, or they originate from dying cells. ${ }^{19}$ Interestingly, these circulating miRNAs are extremely stable, both in blood and after isolation. Numerous studies have shown their potential usefulness as noninvasive diagnostic and prognostic markers in GI cancers. ${ }^{20}$ Seven years ago it was shown that $\mathrm{p} 53$ also regulates the expression of miRNA-encoding genes. ${ }^{8}$ The p53-regulated miRNAs have been implicated 
in the control of various cancer-related processes, such as proliferation, apoptosis, EMT, migration, invasion, and metastasis. Therefore, they may represent important mediators of the tumor suppressive function of p53. In addition, a number of miRNAs can regulate expression and activity of the $\mathrm{p} 53$ protein, either negatively through direct repression of $\mathrm{p} 53$ expression, or positively through the repression of negative regulators of $\mathrm{p} 53$. In this review we summarize the current knowledge about the p53/miRNA network and its role in GI cancers.

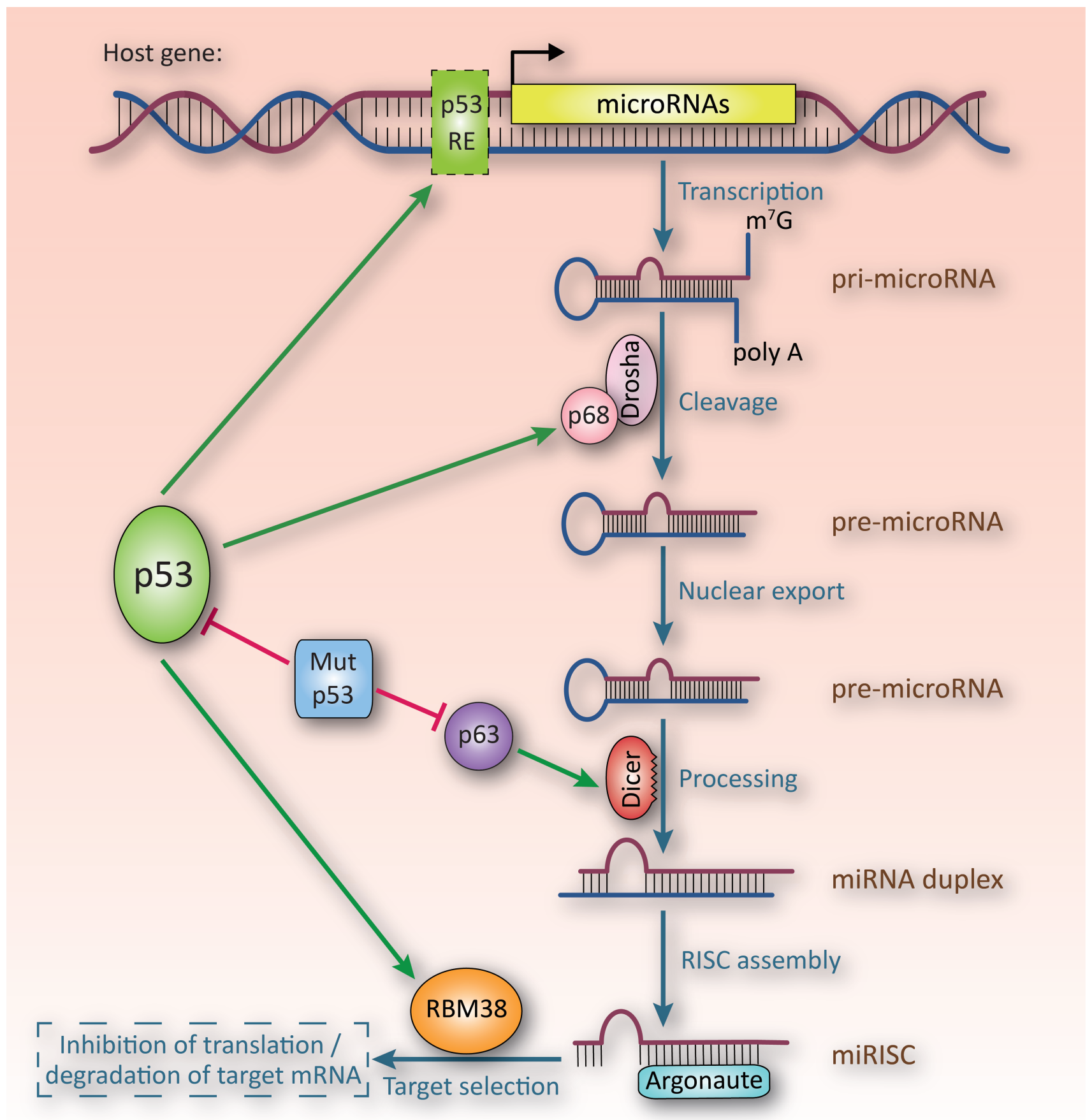

Figure 2 Effects of $\mathrm{p} 53$ on miRNA biogenesis.

Notes: Wild-type p53 (green) regulates miRNA transcription, processing, and target selection. In contrast, mutant p53 (blue) is unable to induce the expression of miRNAs and additionally inhibits the p63-mediated activation of the miRNA processing protein Dicer.

Abbreviations: mRNA, messenger RNA; miRNA, microRNA; pre-microRNA, miRNA precursor molecule; pri-microRNA, primary miRNA; miRISC, miRNA-induced silencing complex; mut, mutant; RE, response element. 


\section{p53 regulated miRNAs}

In 2007, we and other groups identified several miRNAs as direct transcriptional targets of $\mathrm{p} 53 .{ }^{21-27}$ Since then, many of these miRNAs have been validated as important mediators of p53 functions (Table 1 and 2). ${ }^{9}$ p53 regulates the expression of its target miRNAs either on the transcriptional level by direct binding to the promoters of the corresponding genes, or by regulating miRNA processing (Figure 2). It was shown that p53 interacts with the DEAD-box RNA helicase p68 (also known as DDX5) and enhances its interaction with the Drosha complex. As a result, $\mathrm{p} 53$ promotes the processing of specific pri-miRNAs to pre-miRNAs, leading to elevated levels of the respective miRNAs. ${ }^{28}$ Another link between $\mathrm{p} 53$ and miRNA-processing has been observed in conditional Dicer knockout mice. ${ }^{29}$ Dicer deficiency, and therefore incomplete miRNA maturation, induces $\mathrm{p} 53$, which leads to

Table I Summary of changes in expression of p53-pathway-related miRNAs in GI cancers

\begin{tabular}{|c|c|c|c|c|c|c|c|}
\hline & & & \multicolumn{5}{|c|}{ Tumor entity } \\
\hline & & miRNA & CRC & EC & GC & $\mathrm{HCC}$ & $\mathrm{PaC}$ \\
\hline \multirow{19}{*}{ 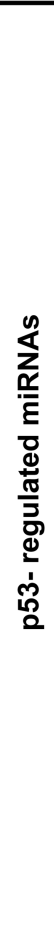 } & \multirow{16}{*}{ 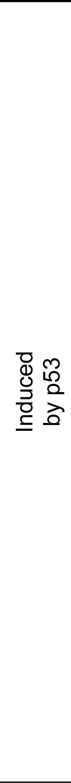 } & miR-34a & $\boldsymbol{\nabla}$ & $\boldsymbol{\nabla}$ & $\boldsymbol{\nabla}$ & $\boldsymbol{\nabla}$ & $\boldsymbol{\nabla}$ \\
\hline & & $\mathrm{miR}-34 \mathrm{~b} / \mathrm{c}$ & $\boldsymbol{\nabla}$ & $\nabla / \Delta$ & $\boldsymbol{\nabla}$ & $\boldsymbol{\nabla}$ & $\boldsymbol{\nabla}$ \\
\hline & & $\mathrm{miR}-15 \mathrm{a} / 16-1$ & $\boldsymbol{\nabla}$ & $\Delta$ & & & \\
\hline & & $\mathrm{miR}-200 \mathrm{c} / 141$ & $\nabla / \Delta$ & $\Delta$ & $\boldsymbol{\nabla}$ & $\boldsymbol{\nabla}$ & \\
\hline & & miR-200a/b/429 & $\boldsymbol{\nabla}$ & $\Delta$ & $\nabla$ & & $\Delta$ \\
\hline & & miR-107 & $\Delta$ & $\boldsymbol{\nabla}$ & $\Delta$ & & $\nabla$ \\
\hline & & miR-145 & $\boldsymbol{\nabla}$ & $\nabla$ & $\nabla$ & $\boldsymbol{\nabla}$ & $\nabla$ \\
\hline & & miR-192/194/215 & $\nabla / \Delta$ & & $\nabla / \Delta$ & & \\
\hline & & miR-29 & $\Delta$ & & $\nabla$ & $\boldsymbol{\nabla}$ & \\
\hline & & miR-605 & & & & & \\
\hline & & miR-149 & $\boldsymbol{\nabla}$ & & $\boldsymbol{\nabla}$ & & \\
\hline & & miR-22 & $\boldsymbol{\nabla}$ & $\Delta$ & $\boldsymbol{\nabla}$ & $\boldsymbol{\nabla}$ & $\Delta$ \\
\hline & & miR-23b & $\boldsymbol{\nabla}$ & $\nabla$ & & $\boldsymbol{\nabla}$ & \\
\hline & & miR-205 & & $\nabla$ & & $\boldsymbol{\nabla}$ & \\
\hline & & $\operatorname{miR}-1246$ & $\nabla / \Delta$ & $\Delta$ & & & \\
\hline & & miR-1204 & & & & & \\
\hline & \multirow{3}{*}{ 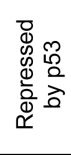 } & miR-17-92 & $\Delta$ & $\Delta$ & $\Delta$ & $\Delta$ & $\Delta$ \\
\hline & & miR-224 & $\nabla / \Delta$ & & & $\Delta$ & \\
\hline & & miR-502 & $\nabla$ & & & & \\
\hline \multirow{12}{*}{ 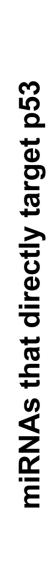 } & & miR-25 & $\Delta$ & $\Delta$ & $\Delta$ & & \\
\hline & & miR-30d & $\Delta$ & & & $\Delta$ & $\Delta$ \\
\hline & & miR-33 & & & & & \\
\hline & & miR-98 & & $\nabla$ & & & \\
\hline & & $\operatorname{miR}-125 a$ & & $\nabla$ & $\nabla$ & $\nabla$ & \\
\hline & & $\operatorname{miR}-125 b$ & $\Delta$ & $\boldsymbol{\nabla}$ & $\nabla / \Delta$ & $\nabla / \Delta$ & $\Delta$ \\
\hline & & miR-150 & $\nabla$ & $\nabla$ & $\Delta$ & & $\nabla$ \\
\hline & & miR-214 & $\Delta$ & $\nabla / \Delta$ & $\Delta$ & $\nabla$ & $\Delta$ \\
\hline & & miR-375 & & $\nabla$ & & & $\nabla$ \\
\hline & & miR-380 & & & & & \\
\hline & & miR-504 & & & & & \\
\hline & & miR-1285 & & & & & \\
\hline
\end{tabular}

Notes: For a more detailed description of the single miRNAs and references see Tables 2 and 3. Green box with $\boldsymbol{\nabla}$ : downregulated in indicated GI tumor type; Red box with $\Delta$ : upregulated in indicated $\mathrm{Gl}$ tumor type; Yellow box with $\boldsymbol{\nabla} / \Delta$ : down- or upregulated in indicated $\mathrm{Gl}$ tumors.

Abbreviations: CRC, colorectal cancer; EC, esophageal cancer; GC, gastric cancer; GI, gastrointestinal; HCC, hepatocellular cancer; miRNA, microRNA; PaC, pancreatic cancer. 
Table 2 Compilation of p53-regulated miRNAs and their alterations in GI cancers

\begin{tabular}{|c|c|c|}
\hline miRNA & Validated by & Clinical and pathological associations in GI cancers \\
\hline \multicolumn{3}{|c|}{ miRNAs induced by $\mathrm{p} 53$} \\
\hline \multirow[t]{4}{*}{ miR-34a } & Luc reporter (mut), qPCR, ChIP24 & $\begin{array}{l}\text { CRC: downregulated in tumors }{ }^{38} \text { and serum; }{ }^{162} \text { Downregulation in metastatic tumors; }{ }^{70,163} \text { CPG } \\
\text { methylation }{ }^{66,67} \text { in metastatic tumors }{ }^{70}\end{array}$ \\
\hline & & EC, HCC: downregulated in tumors; ${ }^{39,41}$ CPG methylation $39,41,164$ \\
\hline & & GC: downregulated in tumors ${ }^{40}$ \\
\hline & & PaC: downregulation associated with poor OS; ${ }^{165}$ CpG methylation ${ }^{66,67}$ \\
\hline \multirow[t]{3}{*}{$\mathrm{miR}-34 \mathrm{~b} / \mathrm{c}$} & Luc reporter (mut), qPCR, ChIP24 & CRC, GC, PaC: CpG methylation ${ }^{67,69}$ \\
\hline & & EC: upregulation associated with advanced tumor stage; ${ }^{166} C_{p}$ methylation ${ }^{164}$ \\
\hline & & HCC: downregulated in tumors ${ }^{41}$ \\
\hline \multirow[t]{3}{*}{ miR-I5a/I6-I } & qPCR, ChIP33 & CRC: miR-16-I down-regulated in tumors; ${ }^{77}$ Downregulation of miR-16-I associated with $\mathrm{pN}$, \\
\hline & & TNM stage, and poor $\mathrm{OS}^{77}$ \\
\hline & & EC: miR-I5a upregulated in tumors ${ }^{167}$ \\
\hline \multirow[t]{6}{*}{$\mathrm{miR}-200 \mathrm{c} / \mathrm{l} 4 \mathrm{I}$} & Luc reporter (mut), qPCR, ChIP32 & CRC: downregulation of miR-200c is associated with poor OS; ${ }^{168} \mathrm{miR}-200 \mathrm{c}$ is downregulated \\
\hline & & in metastatic CRC; ; 169 miR-200c is upregulated in patient serum; ${ }^{12,170}$ Upregulation in serum is \\
\hline & & associated with tumor stage, $\mathrm{pN}$, metastasis, and prognosis; ${ }^{109} \mathrm{CpG}$ methylation ${ }^{171}$ \\
\hline & & EC: miR-200c is upregulated in patient serum; ${ }^{108}$ Upregulation in serum associated with poor RFS 108 \\
\hline & & GC: $m i R-|4|$ is downregulated in tumors ${ }^{172}$ \\
\hline & & HCC: miR-200c is downregulated in tumors: ${ }^{173}$ Downregulation associated with poor RFS ${ }^{174}$ \\
\hline \multirow{5}{*}{$\begin{array}{l}\text { miR-200a/ } \\
200 b / 429\end{array}$} & Luc reporter (mut), qPCR, ChIP32 & CRC: miR-429 is downregulated in tumors ${ }^{175}$; downregulation of miR-200a/429 is associated \\
\hline & & with poor OS; ${ }^{168} C_{P} G$ methylation ${ }^{171}$ \\
\hline & & EC: miR-200a/b are upregulated in tumors ${ }^{167,176}$ \\
\hline & & GC: miR-200a is downregulated in tumors ${ }^{176}$ \\
\hline & & $\mathrm{PaC}: \mathrm{CPG}_{\mathrm{P}}$ hypomethylation and overexpression in tumors ${ }^{177}$ \\
\hline \multirow[t]{5}{*}{ miR-I07 } & Luc reporter (mut), qPCR, ChIP36 & CRC: upregulation associated with metastasis and poor OS $\mathrm{S}^{117}$ \\
\hline & & EC: downregulated in tumors and serum 178 \\
\hline & & GC: upregulated in tumors; Upregulation associated with tumor invasion, stage, $\mathrm{pN}$, and poor \\
\hline & & DFS and $O S^{119}$ \\
\hline & & PaC: $C_{p G}$ methylation ${ }^{179}$ \\
\hline \multirow[t]{2}{*}{ miR-I45 } & Luc reporter (mut), qPCR, ChIP35 & $\begin{array}{l}\text { CRC: downregulated in tumors }{ }^{180,181} \text { and patient stool samples; }{ }^{182} \text { Downregulation associated } \\
\text { with tumor size }\end{array}$ \\
\hline & & EC, GC, HCC, PaC: downregulated in tumors ${ }^{88-90,173,183,184}$ \\
\hline \multirow{4}{*}{$\begin{array}{l}\text { miR-192/ } \\
\text { I94/2I5 }\end{array}$} & qPCR, ChIP 34 & CRC: downregulation of miR-192/194/215 in tumors; $34,185,186$ Downregulation of miR-192/215 \\
\hline & & associated with stage, grade, $\mathrm{pN} ;{ }^{103,186}$ Downregulation of miR-2I5 associated with poor RFS; ${ }^{101}$ \\
\hline & & Upregulation of miR-194 associated with poor RFS and OS ${ }^{187}$ \\
\hline & & $\begin{array}{l}\text { GC: downregulation of miR-194 associated with higher tumor size and stage; }{ }^{188} \text { miR-2I5 } \\
\text { upregulated in tumors }{ }^{189}\end{array}$ \\
\hline \multirow[t]{3}{*}{ miR-29 } & Luc reporter, qPCR ${ }^{149}$ & CRC: upregulated in serum; ${ }^{190}$ Upregulation associated with metastasis and OS ${ }^{191}$ \\
\hline & & GC: downregulated in tumors; Downregulation associated with metastasis ${ }^{152,192}$ \\
\hline & & HCC: downregulated in tumors; Downregulation associated with poor RFS and OS 153,154 \\
\hline miR-605 & Luc reporter (mut), qPCR, ChIPI93 & NA \\
\hline \multirow[t]{3}{*}{ miR-I49 } & Luc reporter (mut), qPCR, ChIP'194 & CRC: downregulated in tumors; ${ }^{195} \mathrm{CpG}$ methylation; ${ }^{196}$ Downregulation associated with \\
\hline & & invasion and poor OS $\mathrm{S}^{196}$ \\
\hline & & GC: downregulated in tumors ${ }^{197}$ \\
\hline \multirow[t]{5}{*}{ miR-22 } & Luc reporter (mut), qPCR, ChIPI98 & CRC: downregulated in tumors and liver metastases; Downregulation associated with poor OS 199 \\
\hline & & $\mathrm{EC}, \mathrm{PaC}$ : upregulated in serum ${ }^{200,201}$ \\
\hline & & GC: downregulated in tumors; ${ }^{202}$ Downregulation associated with tumor stage, $\mathrm{pN}$, metastasis, \\
\hline & & poor OS ${ }^{203}$ \\
\hline & & HCC: downregulated in tumors, Downregulation associated with $\mathrm{pN}$, grade, and poor $\mathrm{OS}^{204,205}$ \\
\hline \multirow[t]{2}{*}{ miR-23b } & Luc reporter (mut), ChIP 206 & EC: downregulation associated with poor prognosis ${ }^{207}$ \\
\hline & & CRC, HCC: downregulated in tumors ${ }^{208,209}$ \\
\hline \multirow[t]{2}{*}{ miR-205 } & Luc reporter (mut), qPCR, ChIP210 & EC: downregulated in tumors, ${ }^{21,212}$ Down-regulation associated with poor prognosis ${ }^{207}$ \\
\hline & & HCC: downregulated in tumors ${ }^{213}$ \\
\hline \multirow[t]{2}{*}{ miR-1246 } & Luc reporter (mut), qPCR, ChIP214 & CRC: downregulated in tumors ${ }^{215}$; Upregulated in patient serum ${ }^{216}$ \\
\hline & & EC: upregulated in tumors ${ }^{217}$ and patient serum ${ }^{218}$ \\
\hline miR-I204 & qPCR, ChIP219 & NA \\
\hline
\end{tabular}

(Continued) 
Table 2 (Continued)

\begin{tabular}{|c|c|c|}
\hline miRNA & Validated by & Clinical and pathological associations in GI cancers \\
\hline \multicolumn{3}{|c|}{ miRNAs repressed by p53 } \\
\hline miR-I7-92 & Luc reporter (mut), qPCR, ChIPI26 & $\mathrm{CRC}_{, 20,221} \mathrm{EC}_{,}^{222,223} \mathrm{GC},{ }^{224,225} \mathrm{HCC}, 226 \mathrm{PaC} ;{ }^{227}$ Upregulated in tumors \\
\hline \multirow[t]{3}{*}{$\operatorname{miR}-224$} & Luc reporter (mut), qPCR, ChIPI24 & CRC: upregulated in tumors; 228,229 Upregulation associated with poor RFS and OS;228,229 \\
\hline & & $\begin{array}{l}\text { Downregulation associated with poor OS; }{ }^{230} \text { Upregulation associated with tumor size, stage, } \\
\text { and metastasis }{ }^{229}\end{array}$ \\
\hline & & HCC: upregulated in tumors ${ }^{231,232}$ \\
\hline miR-502 & Luc reporter ${ }^{125}$ & CRC: downregulated in tumors ${ }^{125}$ \\
\hline
\end{tabular}

Abbreviations: ChIP, chromatin immunoprecipitation; CRC, colorectal cancer; DFS, disease-free survival; EC, esophageal cancer; GC, gastric cancer; GI, gastrointestinal; HCC, hepatocellular cancer; Luc reporter, Luciferase miRNA promoter reporter assay; miRNA, microRNA; mut, mutation in the p53 binding site; NA, not applicable or not analyzed; OS, overall survival; PaC, pancreatic cancer; $\mathrm{PN}$, nodal status; qPCR, quantitative real-time polymerase chain reaction; RFS, relapse-free survival; TNM, tumor, node, metastasis status based classification.

reduced proliferation and premature senescence. Therefore, p53 may operate as a checkpoint to monitor proper miRNA processing. Moreover, expression of Dicer 1 is regulated by the p53 family member p63, which can be inhibited by association with mutant p53. ${ }^{30}$ Finally, p53 also affects miRNA target gene selection by regulating mRNA-binding proteins, such as RNA-binding-motif protein 38, which competes with miRNAs for binding to 3 '-UTRs of mRNAs. ${ }^{31}$ miRNAs transcriptionally induced by p53 include the miR-34, ${ }^{21-26} \mathrm{miR}-200,{ }^{32}$ miR-15a/16-1, ${ }^{33}$ and miR-192/194/215 $5^{34}$ clusters, as well as miR-145 $5^{35}$ and miR-107. ${ }^{36}$ Yet some of these miRNAs, such as miR-16-1, miR-145, and miR-199a-3p, are also regulated on the post-transcriptional level by $\mathrm{p} 53 .^{28,37}$ The expression of the majority of these miRNAs is frequently altered in GI tumors and has been associated with clinical and pathological parameters of various types of GI cancer (Tables 1 and 2).

\section{The miR-34 family}

The miR-34 family includes three members - miR-34a, miR-34b, and miR-34c - which show a marked induction by $\mathrm{p} 53 .{ }^{8}$ MiR-34a is encoded by its own host gene, whereas miR-34b and miR-34c share a common precursor. Both miR-34 genes contain several p53-responsive elements, which are occupied by p53 and mediate activation of miR-34a/b/c after DNA damage. ${ }^{25,26}$ Expression of $\mathrm{miR}-34 \mathrm{a} / \mathrm{b} / \mathrm{c}$ is frequently downregulated in colorectal, ${ }^{38}$ esophageal, ${ }^{39}$ gastric, ${ }^{40}$ and hepatocellular cancers (HCCs). ${ }^{41}$ Consistently, all members of the miR-34 family were shown to suppress tumor growth and metastasis by inhibiting processes that promote cancer, including cell cycle progression, EMT, metastasis, and stemness and by promoting tumor suppressive processes, such as apoptosis and senescence. ${ }^{42}$ MiR-34s regulate these processes through suppressing the expression of their target mRNAs, such as SNAIL, c-Myc, $B c l 2, c-M e t$, and $A x l .{ }^{43}$ The miR-34/p53 axis and its targets are often connected through positive or negative feedback loops that either reinforce the miR-34/p53 signaling or suppress it. For example, a positive feedback loop connects miR-34a and p53 via MDM4 (Figure 3A). MDM4 and its human counterpart HDM4 bind to p53 and inhibit its transcriptional activity. At the same time MDM4/HDM4 are targets of miR-34a. ${ }^{44,45}$ Therefore, the repression of MDM4/HDM4 by miR-34a leads to stabilization of p53 and enhanced expression of miR-34a. Recently, it was shown that in addition to full-length HDM4 that is targeted by miR-34a, a short isoform of HDM4 also exists, which lacks seedmatching sites for miR-34a, thereby evading suppression by miR-34a. ${ }^{45}$ Consistently, this short HDM4 isoform was highly expressed in tumors, where it presumably inhibits the miR-34a/p53 axis.

Furthermore, SIRT1 was shown to mediate activation of p53 by miR-34a. ${ }^{46}$ SIRT1 is an nicotinamide adenine dinucleotide $\left(\mathrm{NAD}^{+}\right)$-dependent deacetylase, which represses p53 activity by deacetylation of p53 protein. Yamakuchi et al showed that SIRT1 is a miR-34 target and that miR-34 induces the activity of $\mathrm{p} 53$ by repressing SIRT 1 in colorectal cancer (CRC) cell lines (Figure 3B). Moreover, miR-34 not only represses the expression of SIRT1, but also suppresses SIRT1 activity by downregulating nicotinamide phosphoribosyltransferase (NAMPT), the rate-limiting enzyme of NAD ${ }^{+}$biosynthesis ${ }^{47}$ Furthermore, SIRT 1 and MYC regulate each other via a positive feedback loop. ${ }^{48,49}$ By repressing both SIRT1 and MYC, miR-34a may therefore efficiently suppress this circuitry.

Another double-negative feedback loop involving miR34a was discovered by Siemens et $a 1,{ }^{50}$ who demonstrated that miR-34a directly targets and suppresses the EMT-inducing transcription factor (EMT-TF) SNAIL, whereas SNAIL represses the $m i R-34 a$ and $m i R-34 b / c$ genes by directly binding to their promoters in CRC cell lines (Figure 3C). By utilizing HCC and CRC cells, Kim et al showed that p53 regulates EMT by inducing members of the miR-200 
A p53 autoregulation

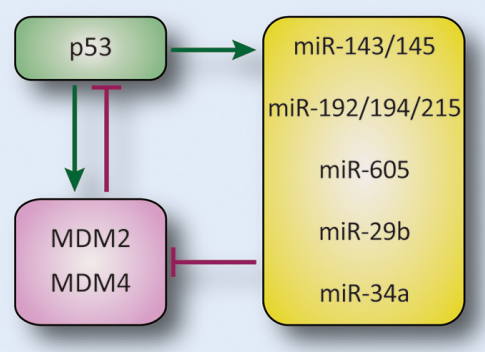

\section{c Invasion / metastasis}
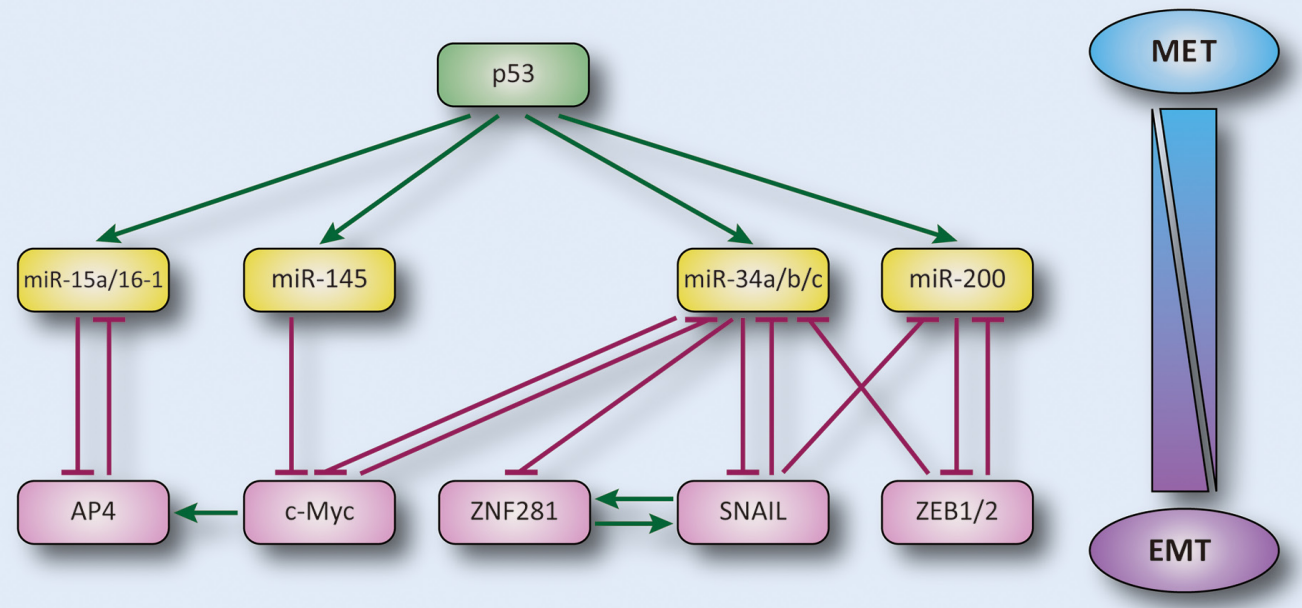

\section{Cancer-associated inflammatory signaling}

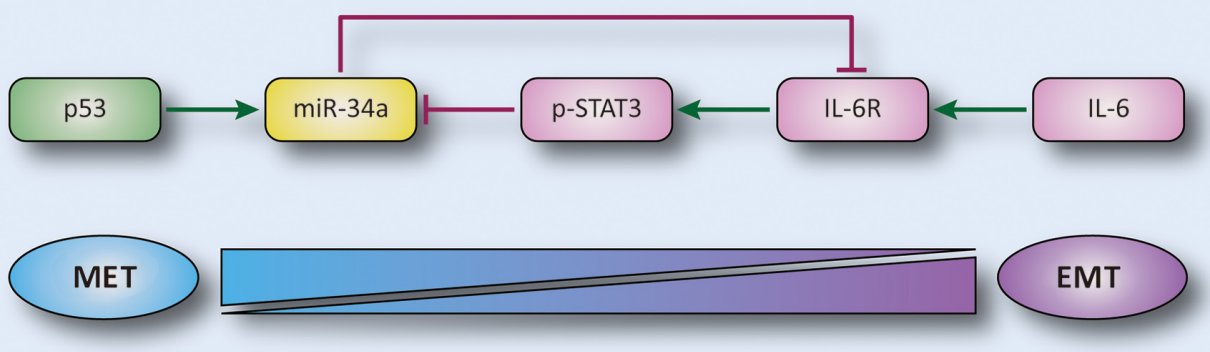

Figure 3 The role of p53/miRNA axis in (A) p53 autoregulation, (B) cancer cell metabolism, (C) invasion, and metastasis, as a result of the regulation of EMT/MET (D) cancer-associated inflammatory signaling.

Notes: Color code: p53/green; miRNAs/yellow; miRNA-targets/red; green arrow/activation; red arrow/inhibition.

Abbreviations: EMT, epithelial-mesenchymal transition; IL-6, interleukin 6; IL-6R, interleukin 6 receptor; MET, mesenchymal-epithelial transition; miRNA, microRNA; $\mathrm{NAD}^{+}$, nicotinamide adenine dinucleotide; NAMPT, nicotinamide phosphoribosyltransferase.

family, ${ }^{32}$ which also represent EMT-regulating miRNAs that suppress EMT by a similar double-negative feedback loop involving the EMT-TFs ZEB1 and ZEB2. ${ }^{51,52}$ Thus, p53 is a key regulator of cellular plasticity by controlling EMT and its counterpart mesenchymal-epithelial transition (MET) through inducing the miRNAs of the miR-34 and miR-200 family (Figure 3C). These miRNAs form two doublenegative feedback loops with their targets SNAIL, ZEB1, and ZEB2 that act as bimodal switches to stabilize either the epithelial or the mesenchymal state. Moreover, ZEB1 
was also shown to repress miR-34a expression by binding to the same E-boxes in the miR-34 promoters as SNAIL, thereby further interconnecting the miR-34/SNAIL and miR-200/ZEB loops. ${ }^{50,53}$ In addition, we recently showed that the zinc-finger 281 (ZNF281) protein is an important miR-34 target with respect to EMT. ${ }^{54}$ We found that the expression of ZNF281 is controlled by miR-34 and SNAIL in a coherent feed-forward-loop, whereby SNAIL and ZNF281 induce each other, whereas miR-34 can directly repress both SNAIL and ZNF281 (Figure 3C). Accordingly, ectopic SNAIL induced EMT by directly activating ZNF281 and concomitantly repressing miR-34a expression, which leads to a further increase in ZNF281 levels. Notably, the induction of ZNF281 by SNAIL was required for SNAIL-induced EMT.

Recently, we demonstrated that inflammation can suppress the expression of miR-34a. ${ }^{55}$ We showed that exposure to the proinflammatory cytokine interleukin-6 (IL-6) results in repression of $m i R-34 a$ via direct binding of the IL-6 effector STAT3 to the first intron of the miR$34 a$ gene. Furthermore, we identified the IL-6 receptor (IL-6R) as a direct target of miR-34a. Further functional analysis revealed the existence of an IL-6R/STAT3/miR$34 \mathrm{a}$ feedback loop (Figure 3D). The activation of this loop was required for EMT, invasion, and metastasis of CRC cell lines and was associated with nodal and distant metastasis in CRC patients. Moreover, in miR-34a-deficient mice, colitis-associated intestinal tumors displayed activation of the loop and, in contrast to tumors in wild-type mice, progressed to invasive carcinomas. Our findings suggest that the activation of the IL-6R/STAT3/miR-34a loop by IL-6 drives cancer cells toward a mesenchymal and invasive phenotype, whereas suppression of the loop by p53 shifts cancer cells toward an epithelial state and prevents EMT and invasion. ${ }^{55}$

Reintroduction of miR-34 into tumors, which lost miR-34 expression, may represent an attractive alternative for cancer treatment. The most common approach for miRNA delivery relies on lipid-based nanoparticles, which contain vectors expressing miRNAs, or 19-23-nt doublestranded mimics of mature miRNAs. These can be administered systemically by intravenous injection or locally into tumors. Several studies have shown that systemic miR-34a delivery suppresses tumor growth in vivo. Using xenograft or genetically engineered mouse models of melanoma, lymphoma, multiple myeloma, breast, prostate, pancreatic, and non-small-cell lung cancer, the authors observed an inhibition of tumor growth by $20 \%$ to $83 \%$ after reintroduc- tion of miR-34a. ${ }^{56}$ Importantly, no severe toxicity caused by systemic miR-34a delivery has been observed in mice. ${ }^{57,58}$ Likewise, no unwanted immune response has been detected, based on serum cytokine levels in immune-competent mice. ${ }^{59}$ Recently, the company Mirna Therapeutics has initiated a clinical Phase I trial of nanoparticle-based delivery of miR$34 \mathrm{a}$ in patients with non-resectable primary liver cancer or metastatic cancer with liver involvement. ${ }^{60}$ Therefore, miR34a may be one of the first miRNA mimics to reach the clinic. Conventional anticancer therapies, such as chemotherapy and treatment with radiation, induce miR-34 expression in human cancer cells with wild-type p53. ${ }^{27}$ However, since the majority of human tumors lack normal p53 function, replacement of miR-34 may enhance the efficacy of standard cancer therapies. Indeed, in prostate, colorectal, and bladder cancer cells, reintroduction of miR-34a precursors enhanced the sensitivity toward camptothecin, paclitaxel, 5-fluorouracil, and cisplatin. ${ }^{61-65}$ Furthermore, lentiviral transduction of miR-34a sensitized gastric and pancreatic cancer cells to radiation and to the chemotherapeutic drugs docetaxel, gemcitabine, cisplatin, and doxorubicin. ${ }^{63,64}$ Moreover, we recently showed that c-Kit is an important miR-34a target that mediates, at least in part, chemosensitization by miR$34 \mathrm{a}$ in CRC cell lines. ${ }^{65}$ Thus, these results suggest that combined treatment with miR-34 mimics may enhance the beneficial effects of conventional cancer therapies.

Downregulation of miR-34 expression in tumors has been frequently attributed to methylation of the $\mathrm{CpG}$ islands present in promoters of $m i R-34 a$ and $m i R-34 b / c{ }^{66-69} \mathrm{CpG}$ methylation is causally involved in repression of $m i R-34$ $a / b / c$, since treatment of CRC cell lines with the demethylating agent 5-aza-2'-deoxycytidine leads to re-expression of $m i R-34 a / b / c .66,68,69$ Moreover, a significant inverse correlation between $m i R-34 a$ methylation and expression has been observed in colon tumors. ${ }^{70,71}$ Therefore, miRNA cancer treatment strategies may rely not only on delivery of synthetic miRNA mimics corresponding to $\mathrm{miR}-34 \mathrm{a} / \mathrm{b} / \mathrm{c}$ into tumors, but also on re-expression of these miRNAs using demethylating agents. Indeed, treatment with BioResponse 3,3'-Diindolylmethane, an experimental anti-androgen prostate cancer drug, resulted in demethylation and re-expression of $m i R-34 a$ in prostate cancer cells. ${ }^{72}$ In a Phase II clinical trial, treatment of prostate cancer patients with BioResponse 3,3'-Diindolylmethane prior to radical prostatectomy led to the re-expression of $m i R-34 a$ as well as repression and nuclear exclusion of its target, the androgen receptor. ${ }^{72,73}$ Several reports showed that $m i R-34$ methylation may also have prognostic value. In our study, $m i R-34 a$ methylation 
in primary CRC was significantly associated with increased formation of lymph node and liver metastases. ${ }^{70}$ Recently, Wu et al analyzed $m i R-34 a / b / c$ methylation in stool samples of 82 CRC patients and 40 controls. ${ }^{74}$ They demonstrated that detection of $m i R-34 a$ and $m i R-34 b / c$ methylation could identify CRC with a remarkable sensitivity of $76.8 \%$ or $95 \%$ and a specificity of $93.6 \%$ or $100 \%$, respectively. Therefore, the detection of miR-34 miRNAs and CpG methylation of $m i R-34$ promoter regions in body fluids or stool represent potential biomarkers which may be utilized for noninvasive screening and diagnosis of cancer in the future.

\section{miR-I5a and miR-I6-I}

Mir-15a and miR-16-1 were the first miRNAs genetically linked to cancer: In 2002, Calin et al showed that $m i R-15 a$ and miR-16-1, which are encoded within an intron of the DLEU2 gene, are frequently deleted and/or downregulated in chronic lymphocytic leukemia. ${ }^{75}$ Notably, a knockout of DLEU2 or of the miR-15a/16-1-bearing intron in mice confirmed that loss of miR-15a/16-1 causes chronic lymphocytic leukemia. ${ }^{76}$ The expression of miR-15a and miR-16-1 is induced by $\mathrm{p} 53$ via transcriptional ${ }^{33}$ and post-transcriptional mechanisms. ${ }^{28}$ Several studies implicated the downregulation or loss of miR-15a and miR-16-1 expression in GI cancers. For example, the expression of miR-16-1 was significantly lower in primary $\mathrm{CRC}$ when compared to the corresponding normal colonic mucosa. ${ }^{77}$ Moreover, decreased miR-16-1 expression was associated with lymph node metastasis and recurrence of colorectal tumors. ${ }^{77}$ Furthermore, ectopic expression of miR-15a and miR-16-1 inhibited the proliferation of pancreatic and colorectal cancer cells ${ }^{78,79}$ and led to a significant inhibition of subcutaneous growth of CRC cell lines in immune-compromised mice. ${ }^{80}$ Interestingly, hepatitis B virus X protein, which is involved in the initiation and progression of HCC downregulates miR-15a/16 expression, suggesting that reintroduction of these miRNAs may be an effective treatment of hepatitis-B-virus-related chronic liver diseases. ${ }^{81} \mathrm{MiR}-15 \mathrm{a}$ and miR-16-1 act tumor suppressive, at least in part, by promoting apoptosis and cell cycle inhibition via targeting the anti-apoptotic protein $\mathrm{Bcl} 2^{82}$ and cell cycle regulators, including CDK6 and cyclin D1, respectively. ${ }^{83,84}$ Recently, we demonstrated that miR-15a/16-1 also inhibit EMT, invasion, and metastasis of CRC cells by directly targeting the EMT-TF AP4. ${ }^{85}$ Interestingly, AP4 itself is a repressor of the DLEU2 gene. We showed that miR-15a/16-1 and the EMT-inducing factor AP $4{ }^{86}$ form a double-negative feedback loop that stabilizes low expression of miR-15a/16-1 and elevated expression of
AP4 in invasive CRC cells and tumors, thereby ultimately promoting CRC metastasis (Figure 3C)..$^{85}$

\section{miR- 45}

p53 controls the expression of miR-145 by two mechanisms: first, p53 directly induces the transcription of the $m i R-145$ gene, ${ }^{35}$ and second, p53 enhances miR-145 maturation via modulation of Drosha-mediated miRNA processing. ${ }^{28,87}$ In line with a regulation by $\mathrm{p} 53$, expression of miR-145 is significantly lower in various tumors that harbor p53 mutations, including esophageal, gastric, pancreatic, colorectal, and bladder cancers. ${ }^{88-92}$ Accordingly, ectopic miR-145 suppresses migration, invasion, and metastasis of gastric and colorectal cancer cells. ${ }^{89,93}$ Moreover, therapeutic polyethylenimine-mediated reintroduction of miR-145 reduces proliferation and increases apoptosis of CRC cells in xenograft mouse models. ${ }^{94}$ The tumor suppressing properties of miR-145 can be partially attributed to the repression of $M Y C$, which represents a direct target of miR-145. ${ }^{35}$ Similar to miR-34, miR-200, and miR-15a/16-1, miR-145 has also been shown to represent a mediator of p53-induced MET, the reversion of EMT (Figure 3C). ${ }^{95}$ Another important oncogenic target of miR-145 is KRAS. ${ }^{96}$ Interestingly, activated KRAS also represses miR-145 via RREB1, thereby forming a feed-forward loop that potentiates RAS signaling. Accordingly, loss of miR-145 is frequently observed in KRAS mutant pancreatic cancers, and restoration of these miRNAs inhibits tumorigenesis. ${ }^{96} \mathrm{Xu}$ et al showed that miR-145 negatively regulates the pluripotency factors OCT4, SOX2, and KLF4, and thereby represses self-renewal and induces differentiation of human embryonic stem cells. ${ }^{97}$ Moreover, the same group reported that the $m i R-145$ promoter is bound and repressed by OCT4, thereby forming a negative feedback loop. ${ }^{97}$ Loss of p53 leads to increased generation of induced pluripotent stem cells and expansion of cancer stem cells. ${ }^{98}$ This effect might at least in part be due to the lack of p53induced $m i R-145$ expression and consequent upregulation of OCT4. Finally, like miR-34a targets MDM4, miR-145 directly targets and represses the p53 inhibitor MDM2. ${ }^{99}$ The result is another positive feed-forward loop that leads to stabilization of p53 and elevated expression of p53induced miRNAs (Figure 3A).

\section{The miR- | 92/miR- | 94/ miR-2 I 5 family}

MiR-192, miR-194, and miR-215 are encoded by two clusters located at two different sites: The miR-194-1/miR-215 cluster 
on chromosome 1 (1q41) and the miR-192/miR-194-2 cluster on chromosome 11 (11q13.1). Both clusters are directly induced by $\mathrm{p} 53 .{ }^{34,100}$ Interestingly, miR-194-1 and miR-194-2 have the same mature sequence, although they are derived from two different precursors on two chromosomal locations. MiR-192 and miR-215 have the same seed sequence, whereas the seed sequence of miR-194 differs. All three miRNAs display decreased expression in colorectal tumors. ${ }^{34}$ Furthermore, low expression of miR-194 and miR-215 significantly correlates with a high probability of relapse and shorter survival in colorectal patients. ${ }^{101}$ MiR-192, miR-194, and miR-215 regulate cell cycle progression and proliferation via the repression of functionally important targets, such as CDC7, MAD2L1, and CUL5. ${ }^{102}$ Moreover, miR-192 suppresses liver metastasis of CRC cells by targeting $B C L 2, Z E B 2$, and $V E G F-A,{ }^{103}$ while miR-194 inhibits EMT in endometrial cells by targeting BMI-1. ${ }^{104}$ Importantly, similar to other p53-induced miRNAs, miR-192, miR-194, and miR-215 also directly target MDM2 and therefore interfere with the autoregulatory MDM2/p53 loop (Figure 3A). ${ }^{100}$

\section{The miR-200 family}

The two genes that give rise to the miR-200c/141 and the 200a/200b/429 miRNAs represent direct p53 target genes. ${ }^{32}$ The members of the miR-200 family are tumor suppressing miRNAs and several studies showed that they play a crucial role in regulating the balance between EMT and MET by forming a double-negative feedback loop with their targets, the EMT-inducers ZEB1 and ZEB2 (Figure 3C). ${ }^{52,105}$ Moreover, miR-200c also suppresses stemness by targeting the stem cell factors KLF4, SOX2, and the polycomb repressor BMI-1. ${ }^{106,107}$ Several studies reported that elevated levels of cell-free, circulating miR-200c and miR-200a in the blood of colorectal, gastric, and esophageal cancer patients are associated with increased tumor stage, presence of metastases, and poor survival. ${ }^{108-112}$ At first sight, this data seems contradictory, since functional studies showed that miR-200s repress EMT, invasion, and metastasis. Yet, recent studies showed that during the formation of metastases, cancer cells undergo MET and re-express EMT-suppressing genes and miRNAs. ${ }^{113}$ Therefore, elevated levels of EMT-suppressing circulating miRNAs, such as miR-200c, might originate from metastases and indicate metastatic dissemination.

\section{miR- 07}

The miRNA miR-107 is encoded by an intron of the p53induced pantothenate kinase 1 (PANK1) gene. ${ }^{36,114}$ Several studies showed that ectopic expression of miR-107 enhances EMT, migration, and promotes metastatic dissemination, whereas the loss of miR-107 represses migration and metastasis of colorectal, breast, and gastric cancer cells. ${ }^{115-118}$ In line with these observations, expression of miR-107 is higher in gastric tumors compared with adjacent normal tissue. ${ }^{119}$ Moreover, high expression of miR-107 correlates with lymph node and distant metastasis as well as poor survival of colorectal, breast, and gastric cancer patients. ${ }^{15-120}$ The pro-metastatic properties of miR-107 are mediated by repression of its targets, the metastasis suppressors DAPK and KLF4. ${ }^{117}$ Furthermore, Martello et al showed that miR-107 targets and represses DICER1, a key component of the miRNA processing machinery, thereby attenuating global miRNA production. ${ }^{115}$ Therefore, elevated levels of miR-107 in tumors may contribute to the global reduction of miRNA abundance that was observed in various cancer types. ${ }^{121}$ In addition to regulation of mRNA targets, miR-107 can also directly interact with and negatively regulate the let-7 miRNA. ${ }^{116}$ Accordingly, miR107 increased the tumorigenic and metastatic potential of human breast cancer cell lines in xenograft mouse models via inhibition of let-7 and upregulation of let-7 targets. ${ }^{116}$ However, others have shown that miR-107 also has tumor suppressing functions by inhibiting cell proliferation and migration of breast cancer, gastric cancer, and glioma cells. ${ }^{120,122,123}$ These tumor suppressing effects could be partially attributed to the miR-107-mediated repression of the response to hypoxia and angiogenesis via targeting of HIF $1 \beta$, resulting in a decreased supply of oxygen and nutrients and subsequent inhibition of tumor growth. ${ }^{114}$ The decrease in functional HIF $1 \alpha$-HIF $1 \beta$ dimers after $p 53$-mediated activation of miR-107 may suppress glycolysis under hypoxic conditions. These results indicate that p53-deficient tumors may be resistant to hypoxia not only because of decreased apoptosis and senescence, but also because of increased HIF1 signalling due to the decrease in miR-107 which results in metabolic and angiogenic adaptation. Altogether, the majority of the current data suggests that miR-107 is an oncogenic miRNA that promotes EMT, migration, and metastasis. However, these observations are at first sight not compatible with the induction of miR-107 by $\mathrm{p} 53$, which would be expected to mediate tumor suppressive functions. A possible explanation may be that p53 induces miR-107 and thereby downregulates DICER 1 to limit the production of p53-induced miRNAs, which would otherwise lead to an unrestrained induction of p53 because of the positive feedback loops these often form with p53. 


\section{p53-repressed miRNAs}

p53 also directly represses certain miRNAs, including miR-224, ${ }^{124}$ miR-502, ${ }^{125}$ and the miR-17-92 cluster. ${ }^{126}$ However, this type of regulation seems to occur less frequently than the induction of tumor suppressive miRNAs by $\mathrm{p} 53$. As expected, miRNAs repressed by p53 mostly have oncogenic functions. The miR-17-92 primary transcript encodes the miRNAs miR-17, miR-18a, miR19a, miR-20a, miR-19b-1, and miR-92a-1. The miR-17-92 clusters undergo genomic amplification and display elevated expression in various cancer entities, including colon cancer. ${ }^{127}$ The miRNAs of the miR-17-92 family promote cell proliferation, increase angiogenesis, promote cell survival, and exhibit strong protumorigenic activities in multiple mouse tumor models. ${ }^{128}$ Yan et al showed that miR-17-92 is repressed upon hypoxia via direct interaction of $\mathrm{p} 53$ with the miR-17-92 promoter. $^{126}$ Due to the strong cell survival promoting properties of miR-17-92 family members, it is likely that the repression of $m i R-17-92$ expression by $\mathrm{p} 53$ plays a role in $\mathrm{p} 53$-induced apoptosis.

\section{Regulation of p53 by miRNAs}

p53 not only regulates the expression and processing of miRNAs, but is also under the control of certain miRNAs. Several miRNAs repress the translation of TP53 mRNA by directly binding to its $3^{\prime}$-UTR (Tables 1 and 3). Since these miRNAs diminish the tumor suppressive activity of p53, they often represent oncomirs. Accordingly, they often exhibit elevated expression in tumors. Similar to the p53-regulated miRNAs the expression of p53-regulating miRNAs is frequently altered in GI tumors (Tables 1 and 3). The first miRNA that was characterized as a direct suppressor of p53 was miR-125b. Le et al. Showed that miR-125b is a negative regulator of $\mathrm{p} 53$ expression and $\mathrm{p} 53$-induced apoptosis during development and stress response. ${ }^{129}$ Furthermore, it has been shown that miR-125 targets several

Table 3 Compilation of miRNAs that directly target p53 and their alterations in Gl cancers

\begin{tabular}{|c|c|c|}
\hline miRNA & Validated by & Clinical and pathological associations in GI cancers \\
\hline \multirow[t]{3}{*}{$\mathrm{miR}-25$} & Luc reporter (mut), qPCR, WB ${ }^{134}$ & CRC: upregulated in tumors; Upregulation associated with invasion, metastasis, poor OS'146 \\
\hline & & EC: upregulated in tumors and serum; ${ }^{233}$ Upregulation associated with $\mathrm{pN}$ and tumor stage ${ }^{137,145}$ \\
\hline & & GC: upregulated in serum ${ }^{234}$ and tumors; ${ }^{235}$ Upregulation associated with tumor progression ${ }^{236,237}$ \\
\hline \multirow[t]{2}{*}{ miR-30d } & Luc reporter (mut), qPCR, WB ${ }^{134}$ & CRC, PaC: gene amplification ${ }^{148}$ \\
\hline & & HCC: upregulated in tumors; Upregulation associated with metastasis ${ }^{238}$ \\
\hline miR-33 & Luc reporter (mut), WB ${ }^{135}$ & NA \\
\hline miR-98 & Luc reporter (mut), WB ${ }^{143}$ & EC: downregulated in tumors; Downregulation associated with tumor stage and $\mathrm{pN}^{239}$ \\
\hline \multirow[t]{3}{*}{ miR-125a } & Luc reporter (mut), WB ${ }^{142}$ & EC: downregulation associated with tumor progression ${ }^{240}$ \\
\hline & & GC: downregulation associated with invasion, metastasis, poor OS $240-242$ \\
\hline & & HCC: downregulated in tumors; Downregulation associated with tumor stage and metastasis ${ }^{243,244}$ \\
\hline \multirow[t]{6}{*}{$\mathrm{miR}-125 \mathrm{~b}$} & Luc reporter (mut), WB'29 & CRC: upregulation associated with tumor size, invasion, poor OS ${ }^{241}$ \\
\hline & & EC: downregulation associated with tumor progression 240 \\
\hline & & GC: upregulation associated with tumor progression; ${ }^{236}$ Downregulation associated with tumor \\
\hline & & progression $^{240}$ \\
\hline & & HCC: upregulated in serum; ${ }^{131}$ Downregulated in tumors ${ }^{244,245}$ \\
\hline & & $\mathrm{PaC}:$ upregulated in tumors $\mathrm{s}^{246}$ \\
\hline \multirow[t]{4}{*}{ miR-I50 } & Luc reporter (mut), WB'138 & CRC: downregulated in tumors; Downregulation associated with poor $\mathrm{OS}^{247}$ \\
\hline & & EC: downregulated in tumors; Downregulation associated with invasion, metastasis, and poor $\mathrm{OS}^{248}$ \\
\hline & & GC: upregulated in tumors ${ }^{249}$ \\
\hline & & $\mathrm{PaC}:$ downregulated in tumors $\mathrm{s}^{250}$ \\
\hline \multirow[t]{5}{*}{ miR-2I4 } & Luc reporter (mut), WB 141 & CRC: upregulation associated with poor $\mathrm{OS}^{236}$ \\
\hline & & EC: upregulated in tumors; ${ }^{251}$ Downregulated in tumors ${ }^{239}$ \\
\hline & & GC: upregulated in tumors; Upregulation associated with poor OS ${ }^{252}$ \\
\hline & & HCC: downregulated in tumors; Downregulation associated with poor RFS and OS ${ }^{253-255}$ \\
\hline & & PaC: upregulated in tumors ${ }^{78}$ \\
\hline \multirow[t]{2}{*}{ miR-375 } & Luc reporter (mut), WB'39 & EC: downregulated in tumors and serum; Downregulation associated with poor OS 145 \\
\hline & & $\mathrm{PaC}:$ downregulated in tumors ${ }^{236}$ \\
\hline miR-380 & Luc reporter, WB ${ }^{136}$ & NA \\
\hline miR-504 & Luc reporter (mut), WB ${ }^{133}$ & NA \\
\hline miR-1285 & Luc reporter (mut), qPCR, WB ${ }^{140}$ & NA \\
\hline
\end{tabular}

Abbreviations: CRC, colorectal cancer; EC, esophageal cancer; GC, gastric cancer; Gl, gastrointestinal; HCC, hepatocellular cancer; Luc reporter, Luciferase reporter assay with p53 3'-UTR; miRNA, microRNA; mut, mutation in the miRNA seed sequence; NA, not applicable or not analyzed; OS, overall survival; PaC, pancreatic cancer; $\mathrm{pN}$, nodal status; qPCR, quantitative real-time polymerase chain reaction; RFS, relapse free survival; WB, Western blot. 
additional components of the p53 network, which include both regulators of apoptosis like Bak1, Igfbp3, Itch, Puma, Prkra, Tp53inp1, and Zac1, and components of the cell cycle machinery such as cyclin C, Cdc25c, Cdkn2c, Edn1, Ppp1ca, and Sel11. ${ }^{130}$ The authors proposed that by regulating proliferative and apoptotic genes, miR-125b buffers and fine-tunes the activity of the p53 network in order to control the balance between proliferation and apoptosis. Recently, it was shown that the levels of miR-125b are significantly higher in the serum of patients with hepatitis-Bvirus-positive HCC and therefore circulating miR-125b may represent a potential non-invasive marker for HCC. ${ }^{131}$ Moreover, elevated expression of miR-125 was also associated with increased tumor size, enhanced invasion, and poor prognosis in CRC patients. ${ }^{132}$ Another miRNA that negatively regulates p53 expression via two seed-matching sequences in the human TP53 3'-UTR is miR-504. ${ }^{133}$ Accordingly, ectopic expression of miR-504 reduced p53 protein levels and impaired p53 functions, especially p53-mediated apoptosis and G1-arrest in response to stress. Furthermore, ectopic expression of miR-504 promoted tumorigenicity of colon cancer cells in mice. ${ }^{133}$ Additionally, miR-25, miR-30d, miR-33, miR-98, miR-150, miR-214, miR-375, miR-380, and miR-1285 also downregulate $\mathrm{p} 53$ protein levels through seed-matching sequences in the $3^{\prime}$-UTR of TP53. ${ }^{134-144}$ Accordingly, ectopic expression of these miRNAs suppresses p53 expression and induces phenotypes that are consistent with a decrease in p53 function, such as reduced apoptosis and senescence, and increased invasion and stem cell selfrenewal. ${ }^{134-137}$ miR-25 levels were increased in esophageal tumors and serum of esophageal cancer patients displayed elevated levels of circulating miR-25. ${ }^{145}$ Moreover, expression of miR-25 was significantly higher in colorectal tumors and elevated levels of miR-25 were associated with increased tumor invasion, lymph node metastasis, distant metastasis, TNM (tumor, node, metastasis status based classification) stage, and poor survival of CRC patients. ${ }^{146} \mathrm{MiR}-30 \mathrm{~d}$ is an important regulator of autophagy, ${ }^{147}$ and interestingly, amplification of the MIR30D gene was found in $\sim 30 \%$ of 1,283 analyzed solid tumors, including bladder, colorectal, and pancreatic cancer. ${ }^{148}$

In addition to the direct repression of p53 by miRNAs, several miRNAs also regulate the expression of p53 indirectly. As described above, the expression of the p53 inhibitors MDM2 and MDM4 is directly repressed by several p53-induced miRNAs: MDM2 is a target of miR-145, miR-192/194/215, miR-605, and miR-29b, whereas MDM4 is targeted by the miR-34 family members (Figure $3 \mathrm{~A}$ ).
Therefore, p53-mediated induction of these miRNAs results in a positive feedback and enhanced p53 activation. In addition, miRNAs of the miR-29 family target the expression of other negative regulators of p53, such as Cdc42, PPM1D, and the regulatory subunit of phosphatidylinositol-3 kinase (PI3K), p85 $\alpha$, and thereby indirectly enhance the levels and activity of p53. ${ }^{149,150}$ In addition, miR-29 is also directly induced by $\mathrm{p} 53,{ }^{149}$ thereby forming a positive feedback loop that is activated during aging and DNA damage, and reinforces p53 effector functions, such as apoptosis and senescence. The members of the miR-29 family are aberrantly expressed in various tumors, including gastric cancer and HCC. ${ }^{151-153}$ Moreover, low expression of miR-29 in HCC was associated with decreased survival. ${ }^{154}$ Furthermore, miR-122, which is expressed exclusively in the liver, is frequently downregulated in liver cancer. ${ }^{155}$ It was shown that miR-122 stabilizes and therefore increases p53 protein levels and activity via downregulation of its target cyclin G1. ${ }^{156}$ Repression of cyclin G1 results in decreased recruitment of the $\mathrm{PP} 2 \mathrm{~A}$ phosphatase to the $\mathrm{p} 53$-inhibitor MDM2. The resulting decrease in MDM2 activity leads to activation of p53. ${ }^{157}$ Interestingly, Cyclin G1 is also directly induced by $\mathrm{p} 53$ and therefore forms a negative feedback loop with p53. ${ }^{158}$ However, therapeutic treatment with miR-122 mimtics might abrogate this loop by downregulation of cyclin G1. Indeed, it has been shown that ectopic miR-122 expression increases the sensitivity of HCC cell lines to the chemotherapeutic agent doxorubicin, which is known to induce p53. ${ }^{156}$ However, it should be noted that miR-122 increases chemosensitivity also in the absence of wild-type p53 and therefore seems to have p53-independent functions.

\section{Conclusion and outlook}

Although numerous links between p53 and miRNAs have been identified, we have only begun to understand the complex interplay between p53 and miRNAs in tumor suppression. Therefore, additional efforts are necessary to uncover more details of the p53/miRNA network. Since p53 has many functions in tumor suppression, future research should focus on identifying which miRNA is responsible for mediating specific p53 functions. It would also be of interest to investigate whether the complete spectrum of tumor suppressing functions of p53, which is frequently lost in tumors, can be restored by the introduction of specific combinations of p53-induced miRNAs. So far, the majority of studies have rather focused on the identification and characterization of single p53-regulated miRNAs. 
A feasible strategy for a comprehensive, genome-wide identification of p53-regulated miRNAs and their target genes has been recently described by us. ${ }^{159}$ This strategy employs a combination of various unbiased genome-wide next generation sequencing screens to simultaneously identify and characterize p53-regulated miRNAs and their targets. By now, knockout mouse models of single p53induced miRNAs have not fully recapitulated the cancerous phenotype of p53 knockout mice, which is characterized by the early onset of lymphomas. ${ }^{160}$ Therefore, it would be interesting to generate genetically modified mice that simultaneously lack multiple p53-related miRNAs to investigate whether loss of certain combinations of miRNAs fully or at least partially mimics the phenotype of p53-knockout mice. Complementarily, p53 knockout mice could be treated with a cocktail of p53-induced miRNAs to investigate whether certain combinations of miRNAs can suppress the tumor promoting effects of p53 loss. In light of the central role of p53-regulated miRNAs or p53-regulating miRNAs for tumor suppression, the introduction of these miRNAs or of miRNA antagonists into tumor cells represents an exciting possibility for novel cancer-therapeutic approaches. Such therapies could also be performed in combination with standard anticancer therapies as has been already shown for miR-34a, which sensitized gastric cancer cells to the chemotherapeutic drugs docetaxel, gemcitabine, cisplatin, and doxorubicin. ${ }^{63}$ A major obstacle for such approaches is the currently low efficiency of miRNA delivery into tumor cells. Therefore, further research is needed to develop more efficient strategies for in vivo miRNA delivery. Promisingly, improved delivery using novel nanoparticles was recently employed to show that a combination of miR-34a mimics and siRNAs directed at mutant oncogenes is more effective than either RNA alone in a pre-clinical mouse model of lung cancer. ${ }^{161}$ Since p53-regulated miRNAs are often inactivated by $\mathrm{CpG}$ methylation in tumors, establishment of routine protocols for detection of methylation of selected promoters of miRNA-encoding genes in body fluids may represent an important aspect of future GI cancer diagnostics.

\section{Disclosure}

The authors report no conflicts of interest in this work.

\section{References}

1. International Agency for Research on Cancer. GLOBOCAN 2012. Estimated Cancer Incidence, Mortality and Prevalence Worldwide in 2012. Geneva: World Health Organization; 2014. Available from: http://globocan. iarc.fr/Pages/fact_sheets_population.aspx. Accessed July 30, 2014.
2. International Agency for Research on Cancer. IARC TP53 Databse Geneva: World Health Organization; 2014. Available from: http://p53. iarc.fr/TP53SomaticMutations.aspx. Accessed July 30, 2014.

3. Vogelstein B, Lane D, Levine AJ. Surfing the p53 network. Nature. 2000;408(6810):307-310.

4. Oren M. Decision making by p53: life, death and cancer. Cell Death Differ. 2003;10(4):431-442.

5. Goh AM, Coffill CR, Lane DP. The role of mutant $\mathrm{p} 53$ in human cancer. J Pathol. 2011;223(2):116-126.

6. Lane D, Levine A. p53 Research: the past thirty years and the next thirty years. Cold Spring Harb Perspect Biol. 2010;2(12):a000893.

7. el-Deiry WS, Kern SE, Pietenpol JA, Kinzler KW, Vogelstein B. Definition of a consensus binding site for p53. Nat Genet. 1992;1(1): 45-49.

8. Hermeking H. p53 enters the microRNA world. Cancer Cell. 2007; 12(5):414-418.

9. Hermeking H. MicroRNAs in the p53 network: micromanagement of tumour suppression. Nat Rev Cancer. 2012;12(9):613-626.

10. Bartel DP. MicroRNAs: genomics, biogenesis, mechanism, and function. Cell. 2004;116(2):281-297.

11. Krol J, Loedige I, Filipowicz W. The widespread regulation of microRNA biogenesis, function and decay. Nat Rev Genet. 2010;11(9):597-610.

12. Yates LA, Norbury CJ, Gilbert RJ. The long and short of microRNA. Cell. 2013;153(3):516-519.

13. Friedman RC, Farh KK, Burge CB, Bartel DP. Most mammalian mRNAs are conserved targets of microRNAs. Genome Res. 2009;19(1): 92-105.

14. Fassan M, Croce CM, Rugge M. miRNAs in precancerous lesions of the gastrointestinal tract. World J Gastroenterol. 2011;17(48): 5231-5239.

15. Song B, Ju J. Impact of miRNAs in gastrointestinal cancer diagnosis and prognosis. Expert Rev Mol Med. 2010;12:e33.

16. Boni V, Bandres E, Zarate R, Colucci G, Maiello E, Garcia-Foncillas J. MicroRNAs as a new potential therapeutic opportunity in gastrointestinal cancer. Oncology. 2009;77 Suppl 1:75-89.

17. Vicentini C, Fassan M, D'Angelo E, et al. Clinical application of microRNA testing in neuroendocrine tumors of the gastrointestinal tract. Molecules. 2014;19(2):2458-2468.

18. Macha MA, Seshacharyulu P, Krishn SR, et al. MicroRNAs (miRNA) as Biomarker(s) for Prognosis and Diagnosis of Gastrointestinal (GI) Cancers. Curr Pharm Des. Epub January 28, 2014.

19. Ajit SK. Circulating microRNAs as biomarkers, therapeutic targets, and signaling molecules. Sensors (Basel). 2012;12(3):3359-3369.

20. Blanco-Calvo M, Calvo L, Figueroa A, Haz-Conde M, Antón-Aparicio L, Valladares-Ayerbes M. Circulating microRNAs: molecular microsensors in gastrointestinal cancer. Sensors (Basel). 2012;12(7):9349-9362.

21. Bommer GT, Gerin I, Feng Y, et al. p53-mediated activation of miRNA34 candidate tumor-suppressor genes. Curr Biol. 2007;17(15): 1298-1307.

22. Chang TC, Wentzel EA, Kent OA, et al. Transactivation of miR-34a by p53 broadly influences gene expression and promotes apoptosis. Mol Cell. 2007;26(5):745-752.

23. Corney DC, Flesken-Nikitin A, Godwin AK, Wang W, Nikitin AY. MicroRNA-34b and MicroRNA-34c are targets of $\mathrm{p} 53$ and cooperate in control of cell proliferation and adhesion-independent growth. Cancer Res. 2007;67(18):8433-8438.

24. He L, He X, Lim LP, et al. A microRNA component of the p53 tumour suppressor network. Nature. 2007;447(7148):1130-1134.

25. Raver-Shapira N, Marciano E, Meiri E, et al. Transcriptional activation of miR-34a contributes to p53-mediated apoptosis. Mol Cell. 2007;26(5):731-743.

26. Tarasov V, Jung P, Verdoodt B, et al. Differential regulation of microRNAs by p53 revealed by massively parallel sequencing: miR-34a is a 53 target that induces apoptosis and G1-arrest. Cell Cycle. 2007;6(13):1586-1593.

27. Tazawa H, Tsuchiya N, Izumiya M, Nakagama H. Tumor-suppressive miR-34a induces senescence-like growth arrest through modulation of the E2F pathway in human colon cancer cells. Proc Natl Acad Sci US A. 2007;104(39):15472-15477. 
28. Suzuki HI, Yamagata K, Sugimoto K, Iwamoto T, Kato S, Miyazono K. Modulation of microRNA processing by p53. Nature. 2009;460(7254): $529-533$.

29. Mudhasani R, Zhu Z, Hutvagner G, et al. Loss of miRNA biogenesis induces p19Arf-p53 signaling and senescence in primary cells. $J$ Cell Biol. 2008;181(7):1055-1063.

30. Su X, Chakravarti D, Cho MS, et al. TAp63 suppresses metastasis through coordinate regulation of Dicer and miRNAs. Nature. 2010;467(7318):986-990.

31. Léveillé N, Elkon R, Davalos V, et al. Selective inhibition of microRNA accessibility by RBM38 is required for p53 activity. Nat Commun. 2011;2:513.

32. Kim T, Veronese A, Pichiorri F, et al. p53 regulates epithelialmesenchymal transition through microRNAs targeting ZEB1 and ZEB2. J Exp Med. 2011;208(5):875-883.

33. Fabbri M, Bottoni A, Shimizu M, et al. Association of a microRNA/ TP53 feedback circuitry with pathogenesis and outcome of B-cell chronic lymphocytic leukemia. JAMA. 2011;305(1):59-67.

34. Braun CJ, Zhang X, Savelyeva I, et al. p53-Responsive micrornas 192 and 215 are capable of inducing cell cycle arrest. Cancer Res. 2008;68(24): 10094-10104.

35. Sachdeva M, Zhu S, Wu F, et al. p53 represses c-Myc through induction of the tumor suppressor miR-145. Proc Natl Acad Sci U S A. 2009; 106(9):3207-3212.

36. Böhlig L, Friedrich M, Engeland K. p53 activates the PANK1/miRNA107 gene leading to downregulation of CDK6 and p130 cell cycle proteins. Nucleic Acids Res. 2011;39(2):440-453.

37. Wang J, He Q, Han C, et al. p53-facilitated miR-199a-3p regulates somatic cell reprogramming. Stem Cells. 2012;30(7):1405-1413.

38. Roy S, Levi E, Majumdar AP, Sarkar FH. Expression of miR-34 is lost in colon cancer which can be re-expressed by a novel agent CDF. $J$ Hematol Oncol. 2012;5:58.

39. Cui X, Zhao Z, Liu D, et al. Inactivation of miR-34a by aberrant $\mathrm{CpG}$ methylation in Kazakh patients with esophageal carcinoma. J Exp Clin Cancer Res. 2014;33:20.

40. Stánitz E, Juhász K, Tóth C, Gombos K, Natali PG, Ember I. Evaluation of MicroRNA expression pattern of gastric adenocarcinoma associated with socioeconomic, environmental and lifestyle factors in northwestern Hungary. Anticancer Res. 2013;33(8):3195-3200.

41. Xie K, Liu J, Chen J, et al. Methylation-associated silencing of microRNA34b in hepatocellular carcinoma cancer. Gene. 2014;543(1):101-107.

42. Wang R, Ma J, Wu Q, et al. Functional role of miR-34 family in human cancer. Curr Drug Targets. 2013;14(10):1185-1191.

43. Rokavec M, Li H, Jiang L, Hermeking H. The p53/miR-34 axis in development and disease. J Mol Cell Biol. 2014;6(3):214-230.

44. Mandke P, Wyatt N, Fraser J, Bates B, Berberich SJ, Markey MP. MicroRNA-34a modulates MDM4 expression via a target site in the open reading frame. PLoS One. 2012;7(8):e42034.

45. Okada N, Lin CP, Ribeiro MC, et al. A positive feedback between p53 and miR-34 miRNAs mediates tumor suppression. Genes Dev. 2014;28(5):438-450.

46. Yamakuchi M, Ferlito M, Lowenstein CJ. miR-34a repression of SIRT1 regulates apoptosis. Proc Natl Acad Sci U SA. 2008;105(36): 13421-13426.

47. Choi SE, Fu T, Seok S, et al. Elevated microRNA-34a in obesity reduces NAD+ levels and SIRT1 activity by directly targeting NAMPT. Aging Cell. 2013;12(6):1062-1072.

48. Menssen A, Hydbring P, Kapelle K, et al. The c-MYC oncoprotein, the NAMPT enzyme, the SIRT1-inhibitor DBC1, and the SIRT1 deacetylase form a positive feedback loop. Proc Natl Acad Sci U SA. 2012;109(4):E187-E196.

49. Marshall GM, Liu PY, Gherardi S, et al. SIRT1 promotes N-Myc oncogenesis through a positive feedback loop involving the effects of MKP3 and ERK on N-Myc protein stability. PLoS Genet. 2011;7(6): e1002135.

50. Siemens H, Jackstadt R, Hünten S, et al. miR-34 and SNAIL form a double-negative feedback loop to regulate epithelial-mesenchymal transitions. Cell Cycle. 2011;10(24):4256-4271.
51. Burk U, Schubert J, Wellner U, et al. A reciprocal repression between ZEB1 and members of the miR-200 family promotes EMT and invasion in cancer cells. EMBO Rep. 2008;9(6):582-589.

52. Gregory PA, Bert AG, Paterson EL, et al. The miR-200 family and miR-205 regulate epithelial to mesenchymal transition by targeting ZEB1 and SIP1. Nat Cell Biol. 2008;10(5):593-601.

53. Ahn YH, Gibbons DL, Chakravarti D, et al. ZEB1 drives prometastatic actin cytoskeletal remodeling by downregulating miR-34a expression. J Clin Invest. 2012;122(9):3170-3183.

54. Hahn S, Jackstadt R, Siemens H, Hünten S, Hermeking H. SNAIL and miR-34a feed-forward regulation of ZNF281/ZBP99 promotes epithelial-mesenchymal transition. EMBO J. 2013;32(23): 3079-3095.

55. Rokavec M, Öner MG, Li H, et al. IL-6R/STAT3/miR-34a feedback loop promotes EMT-mediated colorectal cancer invasion and metastasis. J Clin Invest. 2014;124(4):1853-1867.

56. Bader AG. miR-34 - a microRNA replacement therapy is headed to the clinic. Front Genet. 2012;3:120.

57. Pramanik D, Campbell NR, Karikari C, et al. Restitution of tumor suppressor microRNAs using a systemic nanovector inhibits pancreatic cancer growth in mice. Mol Cancer Ther. 2011;10(8):1470-1480.

58. Craig VJ, Tzankov A, Flori M, Schmid CA, Bader AG, Müller A. Systemic microRNA-34a delivery induces apoptosis and abrogates growth of diffuse large B-cell lymphoma in vivo. Leukemia. 2012; 26(11):2421-2424.

59. Wiggins JF, Ruffino L, Kelnar K, et al. Development of a lung cancer therapeutic based on the tumor suppressor microRNA-34. Cancer Res. 2010;70(14):5923-5930.

60. Mirna Therapeutics, Inc. [homepage on the Internet]. Austin: Mirna Therapeutics, Inc.; 2014. Available from: http://www.mirnarx.com/. Accessed April 30, 2014.

61. Fujita Y, Kojima K, Hamada N, et al. Effects of miR-34a on cell growth and chemoresistance in prostate cancer PC3 cells. Biochem Biophys Res Commun. 2008;377(1):114-119.

62. Vinall RL, Ripoll AZ, Wang S, Pan C-X, deVere White RW. MiR-34a chemosensitizes bladder cancer cells to cisplatin treatment regardless of $\mathrm{p} 53-\mathrm{Rb}$ pathway status. Int $J$ Cancer. 2012;130(11):2526-2538.

63. Ji Q, Hao X, Meng Y, et al. Restoration of tumor suppressor miR-34 inhibits human p53-mutant gastric cancer tumorspheres. BMC Cancer. 2008;8:266.

64. Ji Q, Hao X, Zhang M, et al. MicroRNA miR-34 inhibits human pancreatic cancer tumor-initiating cells. PLoS One. 2009;4(8):e6816.

65. Siemens H, Jackstadt R, Kaller M, Hermeking H. Repression of c-Kit by p53 is mediated by miR-34 and is associated with reduced chemoresistance, migration and stemness. Oncotarget. 2013;4(9): 1399-1415.

66. Lodygin D, Tarasov V, Epanchintsev A, et al. Inactivation of miR-34a by aberrant $\mathrm{CpG}$ methylation in multiple types of cancer. Cell Cycle. 2008;7(16):2591-2600.

67. Vogt M, Munding J, Grüner M, et al. Frequent concomitant inactivation of miR-34a and miR-34b/c by CpG methylation in colorectal, pancreatic, mammary, ovarian, urothelial, and renal cell carcinomas and soft tissue sarcomas. Virchows Arch. 2011;458(3):313-322.

68. Toyota M, Suzuki H, Sasaki Y, et al. Epigenetic silencing of microRNA-34b/c and B-cell translocation gene 4 is associated with CpG island methylation in colorectal cancer. Cancer Res. 2008;68(11): 4123-4132.

69. Suzuki H, Yamamoto E, Nojima M, et al. Methylation-associated silencing of microRNA-34b/c in gastric cancer and its involvement in an epigenetic field defect. Carcinogenesis. 2010;31(12):2066-2073.

70. Siemens H, Neumann J, Jackstadt R, et al. Detection of miR-34a promoter methylation in combination with elevated expression of c-Met and $\beta$-catenin predicts distant metastasis of colon cancer. Clin Cancer Res. 2013;19(3):710-720.

71. Hermeking H. The miR-34 family in cancer and apoptosis. Cell Death Differ. 2010;17(2):193-199. 
72. Kong D, Heath E, Chen W, et al. Epigenetic silencing of miR-34a in human prostate cancer cells and tumor tissue specimens can be reversed by BR-DIM treatment. Am J Transl Res. 2012;4(1):14-23.

73. Östling P, Leivonen SK, Aakula A, et al. Systematic analysis of microRNAs targeting the androgen receptor in prostate cancer cells. Cancer Res. 2011;71(5):1956-1967.

74. Wu XD, Song YC, Cao PL, et al. Detection of miR-34a and miR-34b/c in stool sample as potential screening biomarkers for noninvasive diagnosis of colorectal cancer. Med Oncol. 2014;31(4):894.

75. Calin GA, Dumitru CD, Shimizu M, et al. Frequent deletions and downregulation of micro- RNA genes miR15 and miR16 at 13q14 in chronic lymphocytic leukemia. Proc Natl Acad Sci US A. 2002;99(24): 15524-15529.

76. Klein U, Lia M, Crespo M, et al. The DLEU2/miR-15a/16-1 cluster controls B cell proliferation and its deletion leads to chronic lymphocytic leukemia. Cancer Cell. 2010;17(1):28-40.

77. Qian J, Jiang B, Li M, Chen J, Fang M. Prognostic significance of microRNA-16 expression in human colorectal cancer. World J Surg. 2013;37(12):2944-2949.

78. Zhang XJ, Ye H, Zeng CW, He B, Zhang H, Chen YQ. Dysregulation of miR-15a and miR-214 in human pancreatic cancer. J Hematol Oncol. 2010;3:46.

79. Ma Q, Wang X, Li Z, et al. microRNA-16 represses colorectal cancer cell growth in vitro by regulating the p53/survivin signaling pathway. Oncol Rep. 2013;29(4):1652-1658.

80. Dai L, Wang W, Zhang S, et al. Vector-based miR-15a/16-1 plasmid inhibits colon cancer growth in vivo. Cell Biol Int. 2012;36(8): 765-770.

81. Wu G, Yu F, Xiao Z, et al. Hepatitis B virus X protein downregulates expression of the miR-16 family in malignant hepatocytes in vitro. Br J Cancer. 2011;105(1):146-153.

82. Cimmino A, Calin GA, Fabbri M, et al. miR-15 and miR-16 induce apoptosis by targeting BCL2. Proc Natl Acad Sci USA. 2005;102(39): 13944-13949.

83. Liu Q, Fu H, Sun F, et al. miR-16 family induces cell cycle arrest by regulating multiple cell cycle genes. Nucleic Acids Res. 2008;36(16): 5391-5404.

84. Bonci D, Coppola V, Musumeci M, et al. The miR-15a-miR-16-1 cluster controls prostate cancer by targeting multiple oncogenic activities. Nat Med. 2008;14(11):1271-1277.

85. Shi L, Jackstadt R, Siemens H, Li H, Kirchner T, Hermeking H. p53induced miR-15a/16-1 and AP4 form a double-negative feedback loop to regulate epithelial-mesenchymal transition and metastasis in colorectal cancer. Cancer Res. 2014;74(2):532-542.

86. Jackstadt R, Röh S, Neumann J, et al. AP4 is a mediator of epithelialmesenchymal transition and metastasis in colorectal cancer. $J$ Exp Med. 2013;210(7):1331-1350.

87. Suzuki K, Matsubara H. Recent advances in p53 research and cancer treatment. J Biomed Biotechnol. 2011;2011:978312.

88. Kano M, Seki N, Kikkawa N, et al. miR-145, miR-133a and miR-133b: Tumor-suppressive miRNAs target FSCN1 in esophageal squamous cell carcinoma. Int J Cancer. 2010;127(12):2804-2814.

89. Gao P, Xing a-Y, Zhou GY, et al. The molecular mechanism of microRNA-145 to suppress invasion-metastasis cascade in gastric cancer. Oncogene. 2013;32(4):491-501.

90. Papaconstantinou IG, Manta A, Gazouli M, et al. Expression of microRNAs in patients with pancreatic cancer and its prognostic significance. Pancreas. 2013;42(1):67-71.

91. Slaby O, Svoboda M, Fabian P, et al. Altered expression of miR-21, miR-31, miR-143 and miR-145 is related to clinicopathologic features of colorectal cancer. Oncology. 2007;72(5-6):397-402.

92. Ratert N, Meyer HA, Jung M, et al. miRNA profiling identifies candidate mirnas for bladder cancer diagnosis and clinical outcome. J Mol Diagn. 2013;15(5):695-705.

93. Pagliuca a, Valvo C, Fabrizi E, et al. Analysis of the combined action of miR-143 and miR-145 on oncogenic pathways in colorectal cancer cells reveals a coordinate program of gene repression. Oncogene. 2013;32(40):4806-4813.
94. Ibrahim AF, Weirauch U, Thomas M, Grünweller A, Hartmann RK, Aigner A. MicroRNA replacement therapy for miR-145 and miR-33a is efficacious in a model of colon carcinoma. Cancer Res. 2011;71(15): 5214-5224.

95. Ren D, Wang M, Guo W, et al. Wild-type p53 suppresses the epithelialmesenchymal transition and stemness in PC-3 prostate cancer cells by modulating miR145. Int J Oncol. 2013;42(4):1473-1481.

96. Kent OA, Chivukula RR, Mullendore M, et al. Repression of the miR-143/145 cluster by oncogenic Ras initiates a tumor-promoting feed-forward pathway. Genes Dev. 2010;24(24):2754-2759.

97. Xu N, Papagiannakopoulos T, Pan G, Thomson Ja, Kosik KS MicroRNA-145 regulates OCT4, SOX2, and KLF4 and represses pluripotency in human embryonic stem cells. Cell. 2009;137(4): $647-658$

98. Krizhanovsky V, Lowe SW. Stem cells: The promises and perils of p53. Nature. 2009;460(7259):1085-1086.

99. Zhang J, Sun Q, Zhang Z, Ge S, Han ZG, Chen WT. Loss of microRNA143/145 disturbs cellular growth and apoptosis of human epithelial cancers by impairing the MDM2-p53 feedback loop. Oncogene. 2013;32(1):61-69.

100. Pichiorri F, Suh S-s, Rocci A, et al. Downregulation of p53-inducible microRNAs 192, 194, and 215 Impairs the p53/MDM2 Autoregulatory Loop in Multiple Myeloma Development. Cancer Cell. 2010;18(4):367-381.

101. Li S, Gao J, Gu J, Yuan J, Hua D, Shen L. MicroRNA-215 inhibits relapse of colorectal cancer patients following radical surgery. Med Oncol. 2013;30(2):549.

102. Georges SA, Biery MC, Kim SY, et al. Coordinated regulation of cell cycle transcripts by p53-Inducible microRNAs, miR-192 and miR-215. Cancer Res. 2008;68(24):10105-10112.

103. Geng L, Chaudhuri A, Talmon G, et al. MicroRNA-192 suppresses liver metastasis of colon cancer. Oncogene. Epub November 11, 2013.

104. Dong P, Kaneuchi M, Watari H, et al. MicroRNA-194 inhibits epithelial to mesenchymal transition of endometrial cancer cells by targeting oncogene BMI-1. Mol Cancer. 2011;10:99.

105. Wellner U, Schubert J, Burk UC, et al. The EMT-activator ZEB1 promotes tumorigenicity by repressing stemness-inhibiting microRNAs. Nat Cell Biol. 2009;11(12):1487-1495.

106. Shimono Y, Zabala M, Cho RW, et al. Downregulation of miRNA200c links breast cancer stem cells with normal stem cells. Cell. 2009;138(3):592-603.

107. Lu YX, Yuan L, Xue XL, et al. Regulation of colorectal carcinoma stemness, growth and metastasis by a miR-200c-Sox 2 negative feedback loop mechanism. Clin Cancer Res. 2014;20(10):2631-2642.

108. Tanaka K, Miyata H, Yamasaki M, et al. Circulating miR-200c levels significantly predict response to chemotherapy and prognosis of patients undergoing neoadjuvant chemotherapy for esophageal cancer. Ann Surg Oncol. 2013;20 Suppl 3:S607-S615.

109. Toiyama Y, Hur K, Tanaka K, et al. Serum miR-200c Is a Novel Prognostic and Metastasis-Predictive Biomarker in Patients With Colorectal Cancer. Ann Surg. 2014;259(4):735-743.

110. Valladares-Ayerbes M, Reboredo M, Medina-Villaamil V, et al. Circulating miR-200c as a diagnostic and prognostic biomarker for gastric cancer. J Transl Med. 2012;10:186.

111. Yu H, Duan B, Jiang L, et al. Serum miR-200c and clinical outcome of patients with advanced esophageal squamous cancer receiving platinum-based chemotherapy. Am J Transl Res. 2013;6(1):71-77.

112. Zhang GJ, Zhou T, Liu ZL, Tian HP, Xia SS. Plasma miR-200c and miR-18a as potential biomarkers for the detection of colorectal carcinoma. Mol Clin Oncol. 2013;1(2):379-384.

113. Tsai JH, Donaher JL, Murphy DA, Chau S, Yang J. Spatiotemporal regulation of epithelial-mesenchymal transition is essential for squamous cell carcinoma metastasis. Cancer Cell. 2012;22(6):725-736.

114. Yamakuchi M, Lotterman CD, Bao C, et al. P53-induced microRNA-107 inhibits HIF-1 and tumor angiogenesis. Proc Natl Acad Sci U S A. 2010;107(14):6334-6339. 
115. Martello G, Rosato A, Ferrari F, et al. A MicroRNA targeting dicer for metastasis control. Cell. 2010;141(7):1195-1207.

116. Chen PS, Su JL, Cha ST, et al. miR-107 promotes tumor progression by targeting the let-7 microRNA in mice and humans. J Clin Invest. 2011;121(9):3442-3455.

117. Chen HY, Lin YM, Chung HC, et al. miR-103/107 promote metastasis of colorectal cancer by targeting the metastasis suppressors DAPK and KLF4. Cancer Res. 2012;72(14):3631-3641.

118. Li X, Zhang Y, Shi Y, et al. MicroRNA-107, an oncogene microRNA that regulates tumour invasion and metastasis by targeting DICER1 in gastric cancer. J Cell Mol Med. 2011;15(9):1887-1895.

119. Inoue $T$, Iinuma $H$, Ogawa $E$, Inaba $T$, Fukushima R. Clinicopathological and prognostic significance of microRNA-107 and its relationship to DICER1 mRNA expression in gastric cancer. Oncol Rep. 2012;27(6): $1759-1764$.

120. Feng L, Xie Y, Zhang H, Wu Y. miR-107 targets cyclin-dependent kinase 6 expression, induces cell cycle G1 arrest and inhibits invasion in gastric cancer cells. Med Oncol. 2012;29(2):856-863.

121. Kumar MS, Lu J, Mercer KL, Golub TR, Jacks T. Impaired microRNA processing enhances cellular transformation and tumorigenesis. Nat Genet. 2007;39(5):673-677.

122. Li F, Liu B, Gao Y, et al. Upregulation of MicroRNA-107 induces proliferation in human gastric cancer cells by targeting the transcription factor FOXO1. FEBS Lett. 2014;588(4):538-544.

123. Chen L, Chen XR, Chen FF, et al. MicroRNA-107 inhibits U87 glioma stem cells growth and invasion. Cell Mol Neurobiol. 2013;33(5): 651-657.

124. Liang M, Yao G, Yin M, et al. Transcriptional cooperation between $\mathrm{p} 53$ and NF- $\mathrm{\kappa B}$ p 65 regulates microRNA-224 transcription in mouse ovarian granulosa cells. Mol Cell Endocrinol. 2013;370(1-2):119-129.

125. Zhai H, Song B, Xu X, Zhu W, Ju J. Inhibition of autophagy and tumor growth in colon cancer by miR-502. Oncogene. 2013;32(12): $1570-1579$.

126. Yan HL, Xue G, Mei Q, et al. Repression of the miR-17-92 cluster by $\mathrm{p} 53$ has an important function in hypoxia-induced apoptosis. EMBO J. 2009;28(18):2719-2732.

127. Tsuchida A, Ohno S, Wu W, et al. miR-92 is a key oncogenic component of the miR-17-92 cluster in colon cancer. Cancer Sci. 2011;102(12):2264-2271.

128. Olive V, Jiang I, He L. mir-17-92, a cluster of miRNAs in the midst of the cancer network. Int J Biochem Cell Biol. 2010;42(8):1348-1354.

129. Le MT, Teh C, Shyh-Chang N, et al. MicroRNA-125b is a novel negative regulator of p53. Genes Dev. 2009;23(7):862-876.

130. Le MT, Shyh-Chang N, Khaw SL, et al. Conserved regulation of p53 network dosage by microRNA-125b occurs through evolving miRNAtarget gene pairs. PLoS Genet. 2011;7(9):e1002242.

131. Giray BG, Emekdas G, Tezcan S, et al. Profiles of serum microRNAs; miR-125b-5p and miR223-3p serve as novel biomarkers for HBVpositive hepatocellular carcinoma. Mol Biol Rep. 2014;41(7): 4513-4519.

132. Nishida N, Yokobori T, Mimori K, et al. MicroRNA miR-125b is a prognostic marker in human colorectal cancer. Int J Oncol. 2011;38(5): 1437-1443.

133. Hu W, Chan CS, Wu R, et al. Negative regulation of tumor suppressor p53 by microRNA miR-504. Mol Cell. 2010;38(5):689-699.

134. Kumar M, Lu Z, Takwi AA, et al. Negative regulation of the tumor suppressor p53 gene by microRNAs. Oncogene. 2011;30(7): 843-853.

135. Herrera-Merchan A, Cerrato C, Luengo G, et al. miR-33-mediated downregulation of $\mathrm{p} 53$ controls hematopoietic stem cell self-renewal. Cell Cycle. 2010;9(16):3277-3285.

136. Swarbrick A, Woods SL, Shaw A, et al. miR-380-5p represses p53 to control cellular survival and is associated with poor outcome in MYCNamplified neuroblastoma. Nat Med. 2010;16(10):1134-1140.

137. Xu X, Chen Z, Zhao X, et al. MicroRNA-25 promotes cell migration and invasion in esophageal squamous cell carcinoma. Biochem Biophys Res Commun. 2012;421(4):640-645.
138. Zhang N, Wei X, Xu L. miR-150 promotes the proliferation of lung cancer cells by targeting P53. FEBS Lett. 2013;587(15):2346-2351.

139. Liu Y, Xing R, Zhang X, et al. miR-375 targets the p53 gene to regulate cellular response to ionizing radiation and etoposide in gastric cancer cells. DNA Repair (Amst). 2013;12(9):741-750.

140. Tian S, Huang S, Wu S, Guo W, Li J, He X. MicroRNA-1285 inhibits the expression of p53 by directly targeting its $3^{\prime}$ untranslated region. Biochem Biophys Res Commun. 2010;396(2):435-439.

141. Xu CX, Xu M, Tan L, et al. MicroRNA miR-214 regulates ovarian cancer cell stemness by targeting p53/Nanog. J Biol Chem. 2012;287(42): 34970-34978.

142. Zhang Y, Gao JS, Tang X, et al. MicroRNA 125a and its regulation of the p53 tumor suppressor gene. FEBS Lett. 2009;583(22):3725-3730.

143. Zhang S, Zhang C, Li Y, Wang P, Yue Z, Xie S. miR-98 regulates cisplatin-induced A549 cell death by inhibiting TP53 pathway. Biomed Pharmacother. 2011;65(6):436-442.

144. Wang DT, Ma ZL, Li YL, et al. miR-150, p53 protein and relevant miRNAs consist of a regulatory network in NSCLC tumorigenesis. Oncol Rep. 2013;30(1):492-498.

145. Wu C, Li M, Hu C, Duan H. Clinical significance of serum miR-223, miR-25 and miR-375 in patients with esophageal squamous cell carcinoma. Mol Biol Rep. 2014;41(3):1257-1266.

146. Li X, Yang C, Wang X, Zhang J, Zhang R, Liu R. The expression of miR-25 is increased in colorectal cancer and is associated with patient prognosis. Med Oncol. 2014;31(1):781.

147. Yang X, Zhong X, Tanyi JL, et al. mir-30d Regulates multiple genes in the autophagy pathway and impairs autophagy process in human cancer cells. Biochem Biophys Res Commun. 2013;431(3): 617-622.

148. Li N, Kaur S, Greshock J, et al. A combined array-based comparative genomic hybridization and functional library screening approach identifies mir-30d as an oncomir in cancer. Cancer Res. 2012;72(1): 154-164.

149. Ugalde AP, Ramsay AJ, de la Rosa J, et al. Aging and chronic DNA damage response activate a regulatory pathway involving miR-29 and p53. EMBO J. 2011;30(11):2219-2232.

150. Park SY, Lee JH, Ha M, Nam JW, Kim VN. miR-29 miRNAs activate p53 by targeting p85 alpha and CDC42. Nat Struct Mol Biol. 2009;16(1):23-29.

151. Wang Y, Zhang X, Li H, Yu J, Ren X. The role of miRNA-29 family in cancer. Eur J Cell Biol. 2013;92(3):123-128.

152. Gong J, Li J, Wang Y, et al. Characterization of microRNA-29 family expression and investigation of their mechanistic roles in gastric cancer. Carcinogenesis. 2014;35(2):497-506.

153. Zhu H-T, Dong Q-Z, Sheng Y-Y, et al. MicroRNA-29a-5p is a novel predictor for early recurrence of hepatitis $B$ virus-related hepatocellular carcinoma after surgical resection. PLoS One. 2012;7(12):e52393.

154. Xiong Y, Fang JH, Yun JP, et al. Effects of microRNA-29 on apoptosis, tumorigenicity, and prognosis of hepatocellular carcinoma. Hepatology. 2010;51(3):836-845.

155. Gramantieri L, Fornari F, Callegari E, et al. MicroRNA involvement in hepatocellular carcinoma. J Cell Mol Med. 2008;12(6A): 2189-2204.

156. Fornari F, Gramantieri L, Giovannini C, et al. MiR-122/cyclin G1 interaction modulates p53 activity and affects doxorubicin sensitivity of human hepatocarcinoma cells. Cancer Res. 2009;69(14): 5761-5767.

157. Okamoto K, Li H, Jensen MR, et al. Cyclin G recruits PP2A to dephosphorylate Mdm2. Mol Cell. 2002;9(4):761-771.

158. Okamoto K, Beach D. Cyclin G is a transcriptional target of the p53 tumor suppressor protein. EMBO J. 1994;13(20):4816-4822.

159. Hünten S, Siemens H, Kaller M, Hermeking H. The p53/microRNA network in cancer: experimental and bioinformatics approaches. $A d v$ Exp Med Biol. 2013;774:77-101.

160. Concepcion CP, Han YC, Mu P, et al. Intact p53-dependent responses in miR-34-deficient mice. PLoS Genet. 2012;8(7):e1002797. 
161. Xue W, Dahlman JE,TammelaT, et al. Small RNA combination therapy for lung cancer. Proc Natl Acad Sci USA. 2014;111(34):E3553-3561.

162. Nugent M, Miller N, Kerin MJ. Circulating miR-34a levels are reduced in colorectal cancer. J Surg Oncol. 2012;106(8):947-952.

163. Wu J, Wu G, Lv L, et al. MicroRNA-34a inhibits migration and invasion of colon cancer cells via targeting to Fra-1. Carcinogenesis. 2012;33(3):519-528.

164. Chen $\mathrm{X}, \mathrm{Hu} \mathrm{H}$, Guan $\mathrm{X}$, et al. $\mathrm{CpG}$ island methylation status of miRNAs in esophageal squamous cell carcinoma. Int $J$ Cancer. 2012;130(7):1607-1613.

165. Jamieson NB, Morran DC, Morton JP, et al. MicroRNA molecular profiles associated with diagnosis, clinicopathologic criteria, and overall survival in patients with resectable pancreatic ductal adenocarcinoma. Clin Cancer Res. 2012;18(2):534-545.

166. Harata K, Ishiguro H, Kuwabara Y, Kimura M, Mitsui A. MicroRNA-34b has an oncogenic role in esophageal squamous cell carcinoma. Oncol Lett. 2010;1(4):685-689.

167. Liu SG, Qin XG, Zhao BS, et al. Differential expression of miRNAs in esophageal cancer tissue. Oncol Lett. 2013;5(5):1639-1642.

168. Diaz T, Tejero R, Moreno I, et al. Role of miR-200 family members in survival of colorectal cancer patients treated with fluoropyrimidines. J Surg Oncol. 2014;109(7):676-683.

169. Hur K, Toiyama Y, Takahashi M, et al. MicroRNA-200c modulates epithelial-to-mesenchymal transition (EMT) in human colorectal cancer metastasis. Gut. 2013;62(9):1315-1326.

170. Chen J, Wang W, Zhang Y, Chen Y, Hu T. Predicting distant metastasis and chemoresistance using plasma miRNAs. Med Oncol. 2014; 31(1):799.

171. Davalos V, Moutinho C, Villanueva A, et al. Dynamic epigenetic regulation of the microRNA-200 family mediates epithelial and mesenchymal transitions in human tumorigenesis. Oncogene. 2012;31(16): 2062-2074.

172. Du Y, Xu Y, Ding L, et al. Down-regulation of miR-141 in gastric cancer and its involvement in cell growth. J Gastroenterol. 2009;44(6): 556-561.

173. Karakatsanis A, Papaconstantinou I, Gazouli M, Lyberopoulou A, Polymeneas G, Voros D. Expression of microRNAs, miR-21, miR-31, miR-122, miR-145, miR-146a, miR-200c, miR-221, miR-222, and miR-223 in patients with hepatocellular carcinoma or intrahepatic cholangiocarcinoma and its prognostic significance. Mol Carcinog. 2013;52(4):297-303.

174. Yeh TS, Wang F, Chen TC, et al. Expression profile of microRNA-200 family in hepatocellular carcinoma with bile duct tumor thrombus. Ann Surg. 2014;259(2):346-354.

175. Sun Y, Shen S, Liu X, et al. MiR-429 inhibits cells growth and invasion and regulates EMT-related marker genes by targeting Onecut2 in colorectal carcinoma. Mol Cell Biochem. 2014;390(1-2):19-30.

176. Chen Z, Saad R, Jia P, et al. Gastric adenocarcinoma has a unique microRNA signature not present in esophageal adenocarcinoma. Cancer. 2013;119(11):1985-1993.

177. Li A, Omura N, Hong SM, et al. Pancreatic cancers epigenetically silence SIP1 and hypomethylate and overexpress miR-200a/200b in association with elevated circulating miR-200a and miR-200b levels. Cancer Res. 2010;70(13):5226-5237.

178. Sharma P, Saraya A, Gupta P, Sharma R. Decreased levels of circulating and tissue miR-107 in human esophageal cancer. Biomarkers. 2013;18(4):322-330.

179. Lee KH, Lotterman C, Karikari C, et al. Epigenetic silencing of MicroRNA miR-107 regulates cyclin-dependent kinase 6 expression in pancreatic cancer. Pancreatology. 2009;9(3):293-301.

180. Feng Y, Zhu J, Ou C, et al. MicroRNA-145 inhibits tumour growth and metastasis in colorectal cancer by targeting fascin-1. Br J Cancer. 2014;110(9):2300-2309.

181. Earle JS, Luthra R, Romans A, et al. Association of microRNA expression with microsatellite instability status in colorectal adenocarcinoma. J Mol Diagn. 2010;12(4):433-440.

182. Li JM, Zhao RH, Li ST, et al. Down-regulation of fecal miR-143 and miR-145 as potential markers for colorectal cancer. Saudi Med J. 2012;33(1):24-29.
183. Qiu T, Zhou X, Wang J, et al. MiR-145, miR-133a and miR-133b inhibit proliferation, migration, invasion and cell cycle progression via targeting transcription factor $\mathrm{Sp} 1$ in gastric cancer. FEBS Lett. 2014;588(7):1168-1177.

184. Xing AY, Wang B, Shi DB, et al. Deregulated expression of miR-145 in manifold human cancer cells. Exp Mol Pathol. 2013;95(1):91-97.

185. Chiang Y, Song Y, Wang Z, et al. microRNA-192, -194 and -215 are frequently downregulated in colorectal cancer. Exp Ther Med. 2012;3(3):560-566.

186. Faltejskova P, Svoboda M, Srutova K, et al. Identification and functional screening of microRNAs highly deregulated in colorectal cancer. J Cell Mol Med. 2012;16(11):2655-2666.

187. Kahlert C, Klupp F, Brand K, et al. Invasion front-specific expression and prognostic significance of microRNA in colorectal liver metastases. Cancer Sci. 2011;102(10):1799-1807.

188. Song Y, Zhao F, Wang Z, et al. Inverse association between miR-194 expression and tumor invasion in gastric cancer. Ann Surg Oncol. 2012;19 Suppl 3:S509-S517.

189. Deng $Y$, Huang $Z, X u Y$, et al. MiR-215 modulates gastric cancer cell proliferation by targeting RB1. Cancer Lett. 2014;342(1):27-35.

190. Wang LG, Gu J. Serum microRNA-29a is a promising novel marker for early detection of colorectal liver metastasis. Cancer Epidemiol. 2012;36(1):e61-e67.

191. Tang W, Zhu Y, Gao J, et al. MicroRNA-29a promotes colorectal cancer metastasis by regulating matrix metalloproteinase 2 and E-cadherin via KLF4. Br J Cancer. 2014;110(2):450-458.

192. Chen L, Xiao H, Wang Z-H, et al. miR-29a suppresses growth and invasion of gastric cancer cells in vitro by targeting VEGF-A. $B M B$ Rep. 2014;47(1):39-44.

193. Xiao J, Lin H, Luo X, Luo X, Wang Z. miR-605 joins p53 network to form a $\mathrm{p} 53: \mathrm{miR}-605: \mathrm{Mdm} 2$ positive feedback loop in response to stress. EMBO J. 2011;30(3):524-532.

194. Jin L, Hu WL, Jiang CC, et al. MicroRNA-149*, a p53-responsive microRNA, functions as an oncogenic regulator in human melanoma. Proc Natl Acad Sci U SA. 2011;108(38):15840-15845.

195. Øster B, Linnet L, Christensen LL, et al; COLOFOL steering group. Non-CpG island promoter hypomethylation and miR-149 regulate the expression of SRPX2 in colorectal cancer. Int $J$ Cancer. 2013;132(10):2303-2315.

196. Wang F, Ma YL, Zhang P, et al. SP1 mediates the link between methylation of the tumour suppressor miR-149 and outcome in colorectal cancer. J Pathol. 2013;229(1):12-24.

197. Wang Y, Zheng X, Zhang Z, et al. MicroRNA-149 inhibits proliferation and cell cycle progression through the targeting of ZBTB2 in human gastric cancer. PLoS One. 2012;7(10):e41693.

198. Lin J, Huo R, Xiao L, et al. A novel p53/microRNA-22/Cyr61 axis in synovial cells regulates inflammation in rheumatoid arthritis. Arthritis Rheumatol. 2014;66(1):49-59.

199. Zhang G, Xia S, Tian H, Liu Z, Zhou T. Clinical significance of miR-22 expression in patients with colorectal cancer. Med Oncol. 2012;29(5):3108-3112.

200. Zhang C, Wang C, Chen X, et al. Expression profile of microRNAs in serum: a fingerprint for esophageal squamous cell carcinoma. Clin Chem. 2010;56(12):1871-1879.

201. Ganepola GA, Rutledge JR, Suman P, Yiengpruksawan A, Chang DH. Novel blood-based microRNA biomarker panel for early diagnosis of pancreatic cancer. World $J$ Gastrointest Oncol. 2014;6(1):22-33.

202. Guo MM, Hu LH, Wang YQ, et al. miR-22 is down-regulated in gastric cancer, and its overexpression inhibits cell migration and invasion via targeting transcription factor Sp1. Med Oncol. 2013;30(2):542.

203. Wang W, Li F, Zhang Y, Tu Y, Yang Q, Gao X. Reduced expression of miR-22 in gastric cancer is related to clinicopathologic characteristics or patient prognosis. Diagn Pathol. 2013;8:102.

204. Zhou L, He J, Zhang Y. MicroRNA-22 expression in hepatocellular carcinoma and its correlation with ezrin protein. $J$ Int Med Res. 2013;41(4):1009-1016. 
205. Zhang J, Yang Y, Yang T, et al. microRNA-22, downregulated in hepatocellular carcinoma and correlated with prognosis, suppresses cell proliferation and tumourigenicity. Br J Cancer. 2010;103(8): 1215-1220.

206. Au Yeung CL, Tsang TY, Yau PL, Kwok TT. Human papillomavirus type 16 E6 induces cervical cancer cell migration through the p53/ microRNA-23b/urokinase-type plasminogen activator pathway. Oncogene. 2011;30(21):2401-2410.

207. Zhao BS, Liu SG, Wang TY, et al. Screening of microRNA in patients with esophageal cancer at same tumor node metastasis stage with different prognoses. Asian Pac J Cancer Prev. 2013; 14(1): 139-143.

208. Salvi A, Sabelli C, Moncini S, et al. MicroRNA-23b mediates urokinase and c-met downmodulation and a decreased migration of human hepatocellular carcinoma cells. FEBS J. 2009;276(11):2966-2982.

209. Zhang H, Hao Y, Yang J, et al. Genome-wide functional screening of miR-23b as a pleiotropic modulator suppressing cancer metastasis. Nat Commun. 2011;2:554.

210. Piovan C, Palmieri D, Di Leva G, et al. Oncosuppressive role of p53-induced miR-205 in triple negative breast cancer. Mol Oncol. 2012;6(4):458-472.

211. Gu J, Wang Y, Wu X. MicroRNA in the pathogenesis and prognosis of esophageal cancer. Curr Pharm Des. 2013;19(7):1292-1300.

212. Saad R, Chen Z, Zhu S, et al. Deciphering the unique microRNA signature in human esophageal adenocarcinoma. PLoS One. 2013;8(5): e64463.

213. Zhang T, Zhang J, Cui M, et al. Hepatitis B virus X protein inhibits tumor suppressor miR-205 through inducing hypermethylation of miR-205 promoter to enhance carcinogenesis. Neoplasia. 2013;15(11): $1282-1291$.

214. Zhang Y, Liao JM, Zeng SX, Lu H. p53 downregulates Down syndrome-associated DYRK1A through miR-1246. EMBO Rep. 2011;12(8):811-817

215. Piepoli A, Tavano F, Copetti M, et al. Mirna expression profiles identify drivers in colorectal and pancreatic cancers. PLoS One. 2012;7(3):e33663.

216. Ogata-Kawata $H$, Izumiya $M$, Kurioka D, et al. Circulating exosomal microRNAs as biomarkers of colon cancer. PLoS One. 2014;9(4): e92921.

217. Fu HL, Wu de P, Wang XF, et al. Altered miRNA expression is associated with differentiation, invasion, and metastasis of esophageal squamous cell carcinoma (ESCC) in patients from Huaian, China. Cell Biochem Biophys. 2013;67(2):657-668

218. Takeshita N, Hoshino I, Mori M, et al. Serum microRNA expression profile: miR-1246 as a novel diagnostic and prognostic biomarker for oesophageal squamous cell carcinoma. Br J Cancer. 2013;108(3): 644-652.

219. Barsotti AM, Beckerman R, Laptenko O, Huppi K, Caplen NJ, Prives C. p53-Dependent induction of PVT1 and miR-1204. J Biol Chem. 2012;287(4):2509-2519.

220. Koga Y, Yasunaga M, Takahashi A, et al. MicroRNA expression profiling of exfoliated colonocytes isolated from feces for colorectal cancer screening. Cancer Prev Res (Phila). 2010;3(11):1435-1442.

221. Diosdado B, van de Wiel MA, Terhaar Sive Droste JS, et al. MiR-17-92 cluster is associated with 13q gain and c-myc expression during colorectal adenoma to adenocarcinoma progression. $\mathrm{Br} J$ Cancer. 2009;101(4):707-714.

222. Xu XL, Jiang YH, Feng JG, Su D, Chen PC, Mao WM. MicroRNA-17, microRNA-18a, and microRNA-19a are prognostic indicators in esophageal squamous cell carcinoma. Ann Thorac Surg. 2014;97(3): 1037-1045.

223. Liu M, Wang Z, Yang S, et al. TNF-alpha is a novel target of miR-19a. Int J Oncol. 2011;38(4):1013-1022.

224. Tsujiura M, Komatsu S, Ichikawa D, et al. Circulating miR-18a in plasma contributes to cancer detection and monitoring in patients with gastric cancer. Gastric Cancer. Epub March 14, 2014.
225. Shiotani A, Uedo N, Iishi H, et al. H. pylori eradication did not improve dysregulation of specific oncogenic miRNAs in intestinal metaplastic glands. J Gastroenterol. 2012;47(9):988-998.

226. Shigoka M, Tsuchida A, Matsudo T, et al. Deregulation of miR-92a expression is implicated in hepatocellular carcinoma development. Pathol Int. 2010;60(5):351-357.

227. Morimura R, Komatsu S, Ichikawa D, et al. Novel diagnostic value of circulating miR-18a in plasma of patients with pancreatic cancer. Br J Cancer. 2011;105(11):1733-1740.

228. Zhang GJ, Zhou H, Xiao HX, Li Y, Zhou T. Up-regulation of miR-224 promotes cancer cell proliferation and invasion and predicts relapse of colorectal cancer. Cancer Cell Int. 2013;13(1):104.

229. Liao WT, Li TT, Wang ZG, et al. microRNA-224 promotes cell proliferation and tumor growth in human colorectal cancer by repressing PHLPP1 and PHLPP2. Clin Cancer Res. 2013;19(17): $4662-4672$.

230. Yuan K, Xie K, Fox J, et al. Decreased levels of miR-224 and the passenger strand of miR-221 increase MBD2, suppressing maspin and promoting colorectal tumor growth and metastasis in mice. Gastroenterology. 2013;145(4):853-864. e9.

231. Scisciani C, Vossio S, Guerrieri F, et al. Transcriptional regulation of miR-224 upregulated in human HCCs by NFkappaB inflammatory pathways. J Hepatol. 2012;56(4):855-861.

232. Zhang Y, Takahashi S, Tasaka A, Yoshima T, Ochi H, Chayama K. Involvement of microRNA-224 in cell proliferation, migration, invasion, and anti-apoptosis in hepatocellular carcinoma. J Gastroenterol Hepatol. 2013;28(3):565-575.

233. Komatsu S, Ichikawa D, Hirajima S, et al. Plasma microRNA profiles: identification of miR-25 as a novel diagnostic and monitoring biomarker in oesophageal squamous cell carcinoma. Br J Cancer. 2014.

234. Zhu C, Ren C, Han J, et al. A five-microRNA panel in plasma was identified as potential biomarker for early detection of gastric cancer. Br J Cancer. 2014;110(9):2291-2299.

235. Zhao H, Wang Y, Yang L, Jiang R, Li W. MiR-25 promotes gastric cancer cells growth and motility by targeting RECK. Mol Cell Biochem. 2014;385(1-2):207-213.

236. Ueda T, Volinia S, Okumura H, et al. Relation between microRNA expression and progression and prognosis of gastric cancer: a microRNA expression analysis. Lancet Oncol. 2010;11(2):136-146.

237. Kim BH, Hong SW, Kim A, Choi SH, Yoon SO. Prognostic implications for high expression of oncogenic microRNAs in advanced gastric carcinoma. J Surg Oncol. 2013;107(5):505-510.

238. Yao J, Liang L, Huang S, et al. MicroRNA-30d promotes tumor invasion and metastasis by targeting Galphai2 in hepatocellular carcinoma. Hepatology. 2010;51(3):846-856.

239. Huang S-D, Yuan Y, Zhuang C-W, et al. MicroRNA-98 and microRNA214 post-transcriptionally regulate enhancer of zeste homolog 2 and inhibit migration and invasion in human esophageal squamous cell carcinoma. Mol Cancer. 2012;11:51.

240. Fassan M, Pizzi M, Realdon S, et al. The HER2-miR125a5p/ miR 125b loop in gastric and esophageal carcinogenesis. Hum Pathol. 2013;44(9):1804-1810.

241. Nishida N, Mimori K, Fabbri M, et al. MicroRNA-125a-5p is an independent prognostic factor in gastric cancer and inhibits the proliferation of human gastric cancer cells in combination with trastuzumab. Clin Cancer Res. 2011;17(9):2725-2733.

242. Hashiguchi Y, Nishida N, Mimori K, et al. Down-regulation of miR-125a-3p in human gastric cancer and its clinicopathological significance. Int J Oncol. 2012;40(5):1477-1482.

243. Bi Q, Tang S, Xia L, et al. Ectopic expression of MiR-125a inhibits the proliferation and metastasis of hepatocellular carcinoma by targeting MMP11 and VEGF. PLoS One. 2012;7(6):e40169.

244. Kim JK, Noh JH, Jung KH, et al. Sirtuin7 oncogenic potential in human hepatocellular carcinoma and its regulation by the tumor suppressors MiR-125a-5p and MiR-125b. Hepatology. 2013;57(3): 1055-1067. 
245. Liang L, Wong C-M, Ying Q, et al. MicroRNA-125b suppressesed human liver cancer cell proliferation and metastasis by directly targeting oncogene LIN28B2. Hepatology. 2010;52(5):1731-1740.

246. Bloomston M, Frankel WL, Petrocca F, et al. MicroRNA expression patterns to differentiate pancreatic adenocarcinoma from normal pancreas and chronic pancreatitis. JAMA. 2007;297(17):1901-1908.

247. Ma Y, Zhang P, Wang F, et al. miR-150 as a potential biomarker associated with prognosis and therapeutic outcome in colorectal cancer. Gut. 2012;61(10):1447-1453.

248. Yokobori T, Suzuki S, Tanaka N, et al. MiR-150 is associated with poor prognosis in esophageal squamous cell carcinoma via targeting the EMT inducer ZEB1. Cancer Sci. 2013;104(1):48-54.

249. Wu Q, Jin H, Yang Z, et al. MiR-150 promotes gastric cancer proliferation by negatively regulating the pro-apoptotic gene EGR2. Biochem Biophys Res Commun. 2010;392(3):340-345.

250. Srivastava SK, Bhardwaj A, Singh S, et al. MicroRNA-150 directly targets MUC4 and suppresses growth and malignant behavior of pancreatic cancer cells. Carcinogenesis. 2011;32(12):1832-1839.
251. Zhou Y, Hong L. Prediction value of miR-483 and miR-214 in prognosis and multidrug resistance of esophageal squamous cell carcinoma. Genet Test Mol Biomarkers. 2013;17(6):470-474.

252. Yang TS, Yang XH, Wang XD, Wang YL, Zhou B, Song ZS. MiR-214 regulate gastric cancer cell proliferation, migration and invasion by targeting PTEN. Cancer Cell Int. 2013;13(1):68.

253. Shih TC, Tien YJ, Wen CJ, et al. MicroRNA-214 downregulation contributes to tumor angiogenesis by inducing secretion of the hepatoma-derived growth factor in human hepatoma. $J$ Hepatol. 2012;57(3):584-591.

254. Xia H, Ooi LL, Hui KM. MiR-214 targets $\beta$-catenin pathway to suppress invasion, stem-like traits and recurrence of human hepatocellular carcinoma. PLoS One. 2012;7(9):e44206.

255. Wang J, Li J, Wang X, Zheng C, Ma W. Downregulation of microRNA214 and overexpression of FGFR-1 contribute to hepatocellular carcinoma metastasis. Biochem Biophys Res Commun. 2013;439(1):47-53.
Clinical and Experimental Gastroenterology

\section{Publish your work in this journal}

Clinical and Experimental Gastroenterology is an international, peerreviewed, open access journal, publishing all aspects of gastroenterology in the clinic and laboratory, including: Pathology, pathophysiology of gastrointestinal disease; Investigation and treatment of gastointes tinal disease; Pharmacology of drugs used in the alimentary tract;

\section{Dovepress}

Immunology/genetics/genomics related to gastrointestinal disease. This journal is indexed on CAS. The manuscript management system is completely online and includes a very quick and fair peer-review system. Visit http://www.dovepress.com/testimonials.php to read real quotes from published authors.

Submit your manuscript here: http://www.dovepress.com/clinical-and-experimental-gastroenterology-journal 